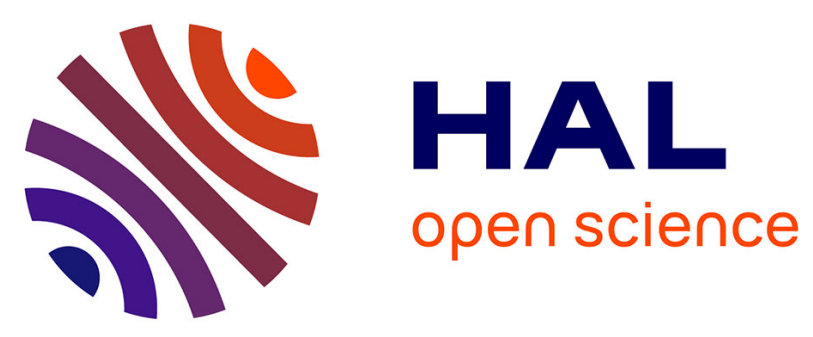

\title{
Nanoscale characterization of aircraft soot: a high-resolution transmission electron microscopy, Raman spectroscopy, X-ray photoelectron and near-edge X-ray absorption spectroscopy study P. Parent, C. Laffon, I. Marhaba, Daniel Ferry, T Z Regier, I. Ortega, B. Chazallon, Y. Carpentier, C. Focsa
}

\section{To cite this version:}

P. Parent, C. Laffon, I. Marhaba, Daniel Ferry, T Z Regier, et al.. Nanoscale characterization of aircraft soot: a high-resolution transmission electron microscopy, Raman spectroscopy, X-ray photoelectron and near-edge X-ray absorption spectroscopy study. Carbon, 2016. hal-02015335

\author{
HAL Id: hal-02015335 \\ https://hal.science/hal-02015335
}

Submitted on 12 Feb 2019

HAL is a multi-disciplinary open access archive for the deposit and dissemination of scientific research documents, whether they are published or not. The documents may come from teaching and research institutions in France or abroad, or from public or private research centers.
L'archive ouverte pluridisciplinaire HAL, est destinée au dépôt et à la diffusion de documents scientifiques de niveau recherche, publiés ou non, émanant des établissements d'enseignement et de recherche français ou étrangers, des laboratoires publics ou privés. 
Nanoscale characterization of aircraft soot: a high-resolution transmission electron microscopy, Raman spectroscopy, X-ray photoelectron and near-edge X-ray absorption spectroscopy study

P. Parent*, C. Laffon, I. Marhaba, D. Ferry

Aix Marseille Université, CNRS, CINaM UMR 7325, 13288, Marseille, France

T.Z. Regier

Canadian Light Source, Saskatoon, SK S7N 2V3, Canada

I.K. Ortega, B. Chazallon, Y. Carpentier, C. Focsa

Laboratoire de Physique des Lasers, Atomes et Molécules (UMR CNRS 8523), Université de

Lille 1 Sciences et Technologies, 59655 Villeneuve d'Ascq, France

Abstract: Particulate emissions from jet aircraft are a significant source of carbonaceous particles in the troposphere and lower stratosphere. Determining their physical structure and chemistry is relevant to assess their impact upon contrail formation, the radiative balance of the atmosphere, and human health. In this report, aircraft soot particles emitted by a recent turbofan engine, the PowerJet SaM146-1S17, fueled with Jet A-1, have been investigated with high-resolution transmission electron microscopy- in imaging, selected area electron diffraction mode, and energy dispersive X-ray spectroscopy -, Raman spectroscopy, X-ray photoelectron spectroscopy and near-edge X-ray absorption spectroscopy. This set of complementary techniques provides detailed structural and chemical information of the surface and the bulk of soot primary particles. Independently of the engine operating regimes, these particles are mainly composed of graphitic layers arranged in onion-like, turbostratic structures. They are poorly oxidized, with a slight enhancement of the oxidation rate at the very surface. The soot's surface also presents a high concentration of unsaturated organic hydrocarbons and structural defects. These results allow a better description of aircraft soot at the atomic level, and may account for a better understanding of ice nucleation in aircraft contrails formation.

Corresponding author: Tel:+33660302807. E-mail: parent@cinam.univ-mrs.fr (Philippe Parent) 


\section{Introduction}

The rapid growth of aviation industry and its expected future expansion have raised environmental concerns about air pollution at the ground-level resulting from airport traffic [1] and climate modifications due to gas and particle emissions at cruising altitudes [2],[3]. Concerning this latter issue, $\mathrm{CO}_{2}$ impact on climate is perhaps the most well understood, but major gaps in our knowledge still exist regarding the effect of the rest of the emissions such as $\mathrm{NO}_{\mathrm{x}}$, water vapor, sulfate and soot aerosol particles [2]. In particular, little is known about aviation-induced clouds, a key in aviation's atmospheric impact, resulting from the formation of linear contrails at the engines exhausts and from the increase of the global concentration of particles that may act as cloud condensation nuclei [2]. In recent models describing the microphysics of ice freezing in cirrus formation [4], two empirical parameters are used to describe the properties of soot: its hydrophilic character, rated as "the critical relative humidity" at which nucleation occurs, and an "active fraction number" describing the ratio of active particles acting as ice nuclei over the total amount of emitted particles. These parameters certainly depend upon complex aspects of the soot particles nanoscale physical properties, such as their shape, composition, inner structure and surface chemistry [5], parameters that vary with fuel type and combustion conditions (engine type, thrust regime, stoichiometry of the combustion reaction) [6]-[11]. A few studies have focused on the characterization of exhaust particles (microstructure, nature of active sites, etc.) from aircraft engines at the nanoscale with sufficient resolution to get a more comprehensive picture of the molecular processes influencing ice nucleation activity [11]-[13]. Popovicheva et al. used combined laboratory techniques (e.g., transmission electron microscopy, Raman spectroscopy, Auger electron spectroscopy, volumetry and gravimetry) to measure graphitic crystallites of $\sim 2 \mathrm{~nm}$ and the occurrence of pores influencing specific adsorbate abilities [12]. They showed significant adsorption enhancement of water compared to non-polar gases on soot produced by a typical aircraft combustor engine. Mazaheri et al. reported particles with diameter in the range 5-100 $\mathrm{nm}$ collected at $70 \mathrm{~m}$ downwind the exhaust of aircraft engines (B737) during takeoff and landing in the airfield at the Brisbane airport [13]. They performed particle-induced X-ray emission and energy dispersive X-ray spectroscopy (EDX) to obtain elemental composition in order to evaluate their toxicity. Vander Wal et al. characterized the micro-structure and surface composition of particles at the exhaust of a CFM-56-2 engine aboard a DC-8 aircraft. They observed systematic variation in the nanostructure (from amorphous to graphitic) with engine power [11]. Elemental composition and organic carbon content were also shown to be dependent on the operating regime. They suggested significant 
oxygen enrichment at the soot surfaces which may potentially render them hydrophilic. A comprehensive characterization of the physical and chemical properties of these aerosol particles is then first require to achieve a full understanding and a realistic description of ice nucleation processes. This is the goal of this work. For this purpose, we have collected particle matter on a sampling line at the exhaust of a turbofan engine (PowerJet, SaM1461S17) burning JET A-1 fuel. The fuel was collected and analyzed for various properties (Table S1, supplementary material) and consistency with specifications for the fuel to be used for emissions certification in International Civil Aviation Organization (ICAO) Annex 16 [14]. The engine was operated on a test facility (SNECMA, Villaroche, France, June 6-11 2013) under controlled atmospheric conditions (temperature, pressure, ambient air cleanliness) according to the ICAO Landing and Take-Off (LTO) cycle: idle, approach, climb and take-off respectively corresponding to $7 \%, 30 \%, 85 \%$ and $100 \%$ of the take-off rated thrust at sea level static $\left(\mathrm{F}_{00}\right)$. An additional point, selected to be representative of cruise conditions and corresponding to $70 \% \mathrm{~F}_{00}$ was also considered. The collected soot samples have been characterized using high-resolution transmission electron microscopy (HRTEM), EDX, micro-Raman spectroscopy, near-edge X-ray absorption spectroscopy (NEXAFS) and $\mathrm{X}$-ray photoemission spectroscopy (XPS).

\section{Experimental}

For Raman spectroscopy, NEXAFS and XPS investigations, the soot samples were collected by inertial impaction both on silicon windows (optical grade, UQG optics) and very high efficiency quartz fiber filters (Pallflex QAT-UP 2500). The deposits form a visible black opaque layer of about $3 \mathrm{~mm}$ in diameter for the $100 \%, 85 \%$ and $70 \% \mathrm{~F}_{00}$ engine regimes. The deposition was fruitless on silicon windows for the $30 \% \mathrm{~F}_{00}$ due to lower engine emission thus no XPS and NEXAFS experiments were done for this regime-, but were possible on a quartz filter for Raman experiments. At the other regimes, the soot samples collected on quartz filters and on silicon windows gave the same Raman spectra, and therefore we assume that the Raman data collected at $30 \% \mathrm{~F}_{00}$ on quartz filter are similar to what would have been obtained on silicon. For HRTEM and EDX experiments, soot was collected by inertial impaction onto holey carbon-coated copper grids (AGAR Scientific). Samples were stored in a desiccator until carrying out the different experiments.

HRTEM images were taken using a JEOL JEM-2010 microscope with an edge-toedge resolution of $0.23 \mathrm{~nm}$ at $200 \mathrm{keV}$. The instrument was operated at $200 \mathrm{keV}$ using a LaB6 filament and the GATAN Image Suite ${ }^{\circledR}$ software v.2.31 was used for microscope operation. 
Observations in the direct space were carried out in the bright field mode and digital images were recorded using a GATAN CCD camera (UltraScan®1000XP model 994). Numerous areas on each grid were surveyed and soot aggregates were randomly selected at low magnification before being studied at higher magnifications for detailed structural analyses. At low magnification (x5000 - x100000) bright field images were obtained only using the 000 transmitted beam and provided morphological information as well as the size of primary particles. At higher magnifications (> x200000) the interference between the 000 and 002 beams gave rise to lattice fringes that reproduce the carbon layers profile, enabling measurements of these carbon layers' length and the distance between them. The JEOL JEM2010 microscope was also used at $200 \mathrm{keV}$ in the diffraction imaging mode with a camera length value of $400 \mathrm{~mm}$. It enabled us accurate measurements of the carbon layers' spacing and a determination of the $\mathrm{C}-\mathrm{C}$ bond length, using respectively the 002 and 110 diffracted beams. Analyses of digital images and measurements were done using Image J [15], which is an open source image processing software designed for scientific multidimensional images (http://imagej.nih.gov/ij/), and results were exported to the program Origin ${ }^{\circledR}$ v8.6. for subsequent plotting and data analyses.

Elemental composition was studied using a X-ray energy dispersive spectrometer (BRUKER, Quantax) equipped with a XFlash ${ }^{\circledR}$ silicon drift detector that has a resolution of $65 \mathrm{eV}$ and $73 \mathrm{eV}$ for the $\mathrm{K} \alpha$ transition of carbon and fluoride respectively.

The Raman measurements were done using an Invia reflex spectrometer from Renishaw equipped with an Olympus microscope (BXFM). The instrument uses excitation radiations with wavelengths of $514.5 \mathrm{~nm}$ and $785 \mathrm{~nm}$. After several test, we found that the spectra obtained with an excitation wavelength of $514.5 \mathrm{~nm}$ had better signal to noise ratio, thus we used that wavelength for the systematic study presented in this work. The scattered light was analyzed by a single dispersive spectrograph equipped with 1800 lines per mm gratings and a Peltier cooled CCD detector. The nominal power of the laser used was $40 \mathrm{~mW}$. Different filters were used to reduce the laser power at the sample surface to avoid thermal effects. The diameter of the laser spot on the surface was around $2 \mu \mathrm{m}$ for the fully focused beam using the 50x magnification objective (numerical aperture 0.5). Using these parameters we estimate the incident intensity on the sample to be $\sim 80 \mu \mathrm{W} / \mu \mathrm{m}^{2}$. This value falls within the recommended limit reported by Lapuerta et al. [16]. The resolution was $1 \mathrm{~cm}^{-1} /$ pixel and the spectrometer was calibrated using the Stokes Raman signal of pure $\mathrm{Si}$ at $520 \mathrm{~cm}^{-1}$. Raman 
spectra were collected from each sample using an integration time of 30 seconds with five accumulated spectra and averaged over 6 different spot positions.

NEXAFS and XPS experiments were carried out on the XPS end-station of the highresolution Spherical Grating Monochromator (SGM) beamline (11 ID-1) of the Canadian Light Source (CLS). NEXAFS data were recorded in the total electron yield (TEY) mode using the drain photocurrent and in partial electron yield (PEY) mode by measuring the Auger electron yield using a SCIENTA 100 hemispherical electron analyzer as a detector, with a pass energy of $50 \mathrm{eV}$. In the PEY measurements, the kinetic energy window was 257-262 eV and 501-506 eV for the $\mathrm{C} 1 \mathrm{~s}$ spectra and the $\mathrm{O} 1 \mathrm{~s}$ spectra, respectively. These kinetic energies correspond to electron inelastic mean free paths (IMFP) in graphite of $0.6 \mathrm{~nm}$ at the $\mathrm{C} 1 \mathrm{~s}$ edge and $1 \mathrm{~nm}$ at the O1s edge [17], and therefore the PEY method probes the 2-3 top-most layers of the soot particles. On the other hand, the TEY mode, based on the drain current, integrates the electron emission over all kinetic energies, resulting in a probed depth of about $5 \mathrm{~nm}$ [18]. Since the typical mean radius of the nanoparticles studied is $7.5 \mathrm{~nm}$, TEY mode can be considered as representative of the bulk of the studied soot particles. The C1s and O1s PEY and TEY NEXAFS data are normalized to the incident beam intensity using the corresponding spectra of a clean Au foil. A highly ordered pyrolytic graphite (HOPG) sample was used as reference for the interpretation of soot spectra and was cleaved in air immediately prior its introduction into the ultrahigh vacuum setup. XPS experiments were carried out with the same hemispherical analyzer, using a pass energy of $50 \mathrm{eV}$ and excitation energies for surveys and $\mathrm{O} 1 \mathrm{~s} / \mathrm{C} 1 \mathrm{~s}$ core levels of $650 / 460 \mathrm{eV}$, respectively. These parameters correspond to IMFP of $0.7 \mathrm{~nm}$ at O1s line and $0.8 \mathrm{~nm}$ at the C1s line [19]. Thus XPS and PEY NEXAFS probe about the same depth. The data were analyzed with the CasaXPS processing software. Quantitative XPS analysis of the oxygen/carbon ratios in the soot samples is possible thanks to the relative sensitivity factors (RSF) of $\mathrm{O} 1 \mathrm{~s}$ and $\mathrm{C} 1 \mathrm{~s}$ determined experimentally. For this, we measured the O1s and C1s XPS intensities at CLS of a soot surrogate film, deposited with a combustion aerosol standard generator (CAST), previously characterized on a laboratory XPS setup for which the C1s and O1s' RSF had been determined on a carbon monoxide multilayer condensed at $20 \mathrm{~K}$.

\section{Results}

3.1. Electron microscopy and X-ray microanalysis

\subsubsection{HRTEM and EDX}


Figure 1 shows HRTEM images of soot primary particles emitted from the SaM1461S17 engine when running at increasing thrust level from $30 \%$ to $100 \% \mathrm{~F}_{00}$. Independently of the engine operation regime, particles exhibit a nanostructure made of concentrically arranged carbonaceous layers, as already reported for aircraft soot particles [11], [20]. Figure 2 shows the distribution of the carbonaceous layer lengths with increasing engine power, measured individually on more than 2000 layers for each sample. These distributions allow the quantification for the layer lateral extensions and we present the parameters of the lognormal curves that give the best fit of our experimental data in Table 1 .

\begin{tabular}{lllll}
\hline & \multicolumn{4}{c}{ Engine thrust level } \\
& $\mathbf{3 0 \%} \mathbf{F}_{\mathbf{0 0}}$ & $\mathbf{7 0 \%} \mathbf{F}_{\mathbf{0 0}}$ & $\mathbf{8 5 \%} \mathbf{F}_{\mathbf{0 0}}$ & $\mathbf{1 0 0 \%} \mathbf{F}_{\mathbf{0 0}}$ \\
\hline Number of measurements & 2221 & 2030 & 2130 & 2128 \\
$l_{m}(\mathrm{~nm})$ & $3.66 \pm 0.07$ & $2.54 \pm 0.02$ & $3.04 \pm 0.05$ & $2.94 \pm 0.04$ \\
$l_{g}(\mathrm{~nm})$ & $4.97 \pm 0.09$ & $3.59 \pm 0.04$ & $4.27 \pm 0.07$ & $4.10 \pm 0.05$ \\
$\sigma_{g}$ & $1.74 \pm 0.03$ & $1.80 \pm 0.02$ & $1.79 \pm 0.02$ & $1.78 \pm 0.02$ \\
\hline
\end{tabular}

Table 1. Number of measurements and evolution of the lognormal distribution parameters with increasing engine power: mode $l_{m}$, geometric length $l_{g}$ and geometric standard deviation $\sigma_{g}$

In this table, the mode of the distribution $l_{m}$ corresponds to the maximum of the lognormal distribution that is the most often encountered carbon layer length value in the set of measurements. Its value varies between 2.54 to $3.66 \mathrm{~nm}$ at the various engine powers, which is in the same order of magnitude but much higher than $l_{m}$ values of about $\sim 0.7 \mathrm{~nm}$ presented by Vander Wal et al. for a CFM-56-2 engine running at power levels between 4 to $100 \% \mathrm{~F}_{00}$ [11]. The geometric length $l_{g}$ corresponds to the median value of the measurements and it ranges from 3.59 to $4.97 \mathrm{~nm}$ for engine thrust levels between $30 \%-100 \% \mathrm{~F}_{00}$.

Soot particles were analyzed by EDX for determining their elemental bulk chemical composition. Figure 3 shows illustrative EDX spectra of particles collected at engine power $70 \%$ and $85 \% \mathrm{~F}_{00}$. Analyses reveal that particles are free of metallic elements and are systematically made of carbon, oxygen and traces of sulfur, the presence of copper and silicon in the spectra being due to the TEM grids. Table 2 indicates respective amounts of $\mathrm{C}, \mathrm{O}$ and $\mathrm{S}$ for all the investigated engine regimes and also shows that the elemental bulk chemical 
composition does not evolve with the engine thrust. One can therefore consider from our results an average elemental chemical composition of $\sim 97 \%$ of $\mathrm{C}, \sim 3 \%$ of $\mathrm{O}$, and atomic traces of $\mathrm{S}$.

\begin{tabular}{lllll}
\hline & \multicolumn{4}{c}{ Engine thrust level } \\
& $\mathbf{3 0 \%} \mathbf{F}_{\mathbf{0 0}}$ & $\mathbf{7 0 \%} \mathbf{F}_{\mathbf{0 0}}$ & $\mathbf{8 5 \%} \mathbf{F}_{\mathbf{0 0}}$ & $\mathbf{1 0 0 \%} \mathbf{F}_{\mathbf{0 0}}$ \\
\hline $\mathrm{C}($ atom\%) & $96.3 \pm 0.8$ & $96.7 \pm 0.9$ & $96.9 \pm 0.8$ & $97.1 \pm 0.7$ \\
$\mathrm{O}($ atom\%) & $3.6 \pm 0.6$ & $3.2 \pm 0.9$ & $3.0 \pm 0.9$ & $2.8 \pm 0.8$ \\
$\mathrm{~S}($ atom\%) & $0.09 \pm 0.02$ & $0.08 \pm 0.03$ & $0.07 \pm 0.05$ & $0.07 \pm 0.03$ \\
\hline
\end{tabular}

Table 2. Evolution of elemental bulk chemical composition of soot particles with increasing engine power.

\subsubsection{TEM diffraction}

HRTEM images allow measurements of the lattice spacing $d_{002}$ between carbon layers in the real space but we determine its value from the electron diffraction pattern. We present in Figure $4 a$ a selected-area electron diffraction (SAED) pattern of soot particles, where concentric blurred rings are clearly visible, and its corresponding radial intensity profile (Figure $4 b$ ) that exhibits maxima corresponding to the lattice spacing $d_{002}, d_{100}$ and $d_{110}$ (Figure 5) [21]. It is noteworthy that the lack of distinct reflections in the SAED pattern indicates that the particles structure is poorly ordered. This typical SAED pattern of soot particles is consistent with a turbostratic structure (Figure 5) where a few graphitic carbonaceous layers having small lateral extensions are stacked, with a random rotation angle between them, to form basic structural units [22] that are more or less concentrically oriented in space to form an onion-like structure [23]. We do not observe any shape variation of SAED patterns with the engine operation regime. We present in Table 3 the measured values of lattice spacing as well as the carbon-carbon bonding length that is determined from $d_{110}$. Interlayer spacing $d_{002}$ are of about $\sim 0.36 \mathrm{~nm}$ independently of the engine regime, which is larger than the (002) crystal lattice spacing of $0.335 \mathrm{~nm}$ in graphite, but still in the common range 0.34-0.42 $\mathrm{nm}$ for soot originating from combustion processes [24]. The $d_{100}$ and $d_{110}$ lattice spacing values allow us to determine the carbon first-neighbor atomic distances within the graphene-like layers. Using $d_{110}$ values leads to carbon bonding lengths of $0.14 \mathrm{~nm}$, which is slightly shorter but very close to that of graphite $\left(l_{C-C}=0.142 \mathrm{~nm}\right)$, as usually determined for atmospheric soot [25]. 


\begin{tabular}{lllll}
\hline & \multicolumn{4}{c}{ Engine thrust level } \\
& $\mathbf{3 0 \%} \mathbf{F}_{\mathbf{0 0}}$ & $\mathbf{7 0 \%} \mathbf{F}_{\mathbf{0 0}}$ & $\mathbf{8 5 \%} \mathbf{F}_{\mathbf{0 0}}$ & $\mathbf{1 0 0 \%} \mathbf{F}_{\mathbf{0 0}}$ \\
\hline$d_{002}(\mathrm{~nm})$ & 0.37 & 0.36 & 0.37 & 0.36 \\
$d_{100}(\mathrm{~nm})$ & 0.21 & 0.21 & 0.21 & 0.21 \\
$d_{110}(\mathrm{~nm})$ & 0.12 & 0.12 & 0.12 & 0.12 \\
$l_{C-C}(\mathrm{~nm})$ & 0.14 & 0.14 & 0.14 & 0.14 \\
\hline
\end{tabular}

Table 3. Values of lattice spacing $d_{002}, d_{100,} d_{110}$ and the carbon-carbon bonding 's length $l_{C-C}$ with increasing engine power

\subsection{Raman spectroscopy}

Figure $6 a$ shows the $800-2000 \mathrm{~cm}^{-1}$ spectral region of the first-order band of the soot samples' Raman spectra for each engine regime. Overall, the spectra are close to each other and can be fitted with the same band distribution (the spectral parameters are summarized in Table S2 of the supplementary material). The most intense bands are D1 and D3; D2 and G have lower and similar intensities, and D4 is the weakest band (Figure 6b). The deconvolution of soot Raman spectra is generally challenging [26]-[29]. D2 and G bands overlap in most of the cases, and it is sometimes difficult to separate their contributions [26]. The D3 band is broad and its fitted position might change over several $\mathrm{cm}^{-1}$, so in some cases its position needs to be fixed to obtain reliable results [27]. In addition, there are several combinations of band shapes used for deconvolution in the literature. Sadezky et al. tested nine different band shape combinations and found that best results were achieved with four Lorentzian functions for D1, D2, D4, and G, and one Gaussian function for D3 band [26]. We also use this approach that has been successfully applied in different works [30]-[32] and led to a reproducible characterization of soot spectra [33]. Fit results are sensitive to the initial guess position chosen for the different bands [26]. To overcome this difficulty, and improve the fitting protocol, a robust least square approach was applied. It consists in processing hundred minimization runs by changing the initial positions of the bands randomly from run to run in the range of $+/-5 \mathrm{~cm}^{-1}$ from the values reported by Sadezky et al. [26]. After the random runs, we selected the fit with lower root-mean-square (RMS) fitting error.

The $\mathrm{G}$ band at $1580 \mathrm{~cm}^{-1}$ is solely observed in single crystal graphite, which belongs to $D_{6 h}^{4}$ symmetry with Raman active vibrational modes of the types $2 \mathrm{E}_{2 \mathrm{~g}}$. In more complex carbonaceous material the D1 and D2 bands appear as the number of defects increases. The D1 band at $1350 \mathrm{~cm}^{-1}$ corresponds to a breathing mode of carbon rings of $\mathrm{A}_{1 \mathrm{~g}}$ symmetry [34], 
which is Raman inactive in the case of perfect infinite graphitic planes. It becomes active and observable in Raman spectroscopy for finite graphene layers (or when borders exist, i.e. in small graphene sheets, or/and when holes/vacancies are present), as the finiteness induces a symmetry breaking and a relaxation of the selection rule [35],[36]. The D2 band at $1620 \mathrm{~cm}^{-1}$ is generally assigned to lattice vibrations analogous to that of the $\mathrm{G}$ band, but involving isolated graphene layers, i.e. not directly sandwiched between two other layers [37]. When the carbonaceous material is highly disordered, two further bands D3 and D4 appear. The D3 band at $1500 \mathrm{~cm}^{-1}$ is generally very broad and is often assigned to amorphous carbon [38][40]. In general, the D4 band is characteristic of highly disorder materials like soot or coal chars [26], [40]-[43]. Its origin is still under debate; some authors assign it to carbon $\mathrm{sp}^{3}-\mathrm{sp}^{2}$ at the periphery of the crystallites, or to $\mathrm{C}-\mathrm{C}$ and $\mathrm{C}=\mathrm{C}$ stretching vibrations in polyene-like structures [40]-[42].

Our HRTEM observations show that the soot primary particles are made of small graphene units with length varying between 2.54 and $3.66 \mathrm{~nm}$ at various engine powers, and organized in a turbostratic structure. In Raman spectroscopy, the crystallite size $L_{a}$ can be also estimated by the relationship [44]:

$$
L_{a}(n m)=\left(2.410^{-10}\right) \lambda_{\text {laser }}^{4}\left(A_{D} / A_{G}\right)^{-1}
$$

where $\lambda_{\text {laser }}$ correspond to the laser excitation wavelength, in this case $514 \mathrm{~nm}$. Using D1/G, we obtain the lengths shown in Table 4. This shows a relatively good agreement with the HRTEM results (i.e., same order of magnitude as that found for $l_{m}$ (Table 1)), though the observed trend seems to be opposite to the one observed in HRTEM. In any case, it has to be noted that the sizes of the crystallites are close to Eq. (1) validity limit and that the difference found between different samples falls within the standard deviations, so it is risky to draw any conclusion on the trends observed.

\begin{tabular}{lc}
\hline Sample & Size \\
\hline $30 \% \mathrm{~F}_{00}$ & $2.67 \pm 0.30 \mathrm{~nm}$ \\
$70 \% \mathrm{~F}_{00}$ & $2.85 \pm 0.58 \mathrm{~nm}$ \\
$85 \% \mathrm{~F}_{00}$ & $2.73 \pm 0.45 \mathrm{~nm}$ \\
$100 \% \mathrm{~F}_{00}$ & $3.06 \pm 0.53 \mathrm{~nm}$ \\
\hline
\end{tabular}

Table 4. Crystallite size calculated with equation (1) using D1/G. 
The pictures provided by the HRTEM experiments allow us to assume that the Raman spectra can be closely approximated as a sum of Raman spectra of individual polycyclic aromatic macromolecules having sizes close or equal to $L_{a}$. This approach has been successfully used by Negri et al. in carbon materials containing $\mathrm{sp}^{2}$ islands [45]. For the vibrational quantum calculations presented hereafter the model molecule chosen is $\mathrm{C}_{216} \mathrm{H}_{36}$. It is a large polycyclic aromatic hydrocarbon $(\mathrm{PAH})$ molecule with a diameter of $\sim 2.7 \mathrm{~nm}$ (Figure S1, supplementary material), which is close to the average crystallite size measured in HRTEM and in Raman spectroscopy using equation (1). Obviously soot particles are more complex than such an ideal assembly of identical polyaromatic units; they have a poor level of organization (broader size distribution, bends, tortuosity, defects), which manifests as large bandwidths of the Raman bands.

Due to the size of the model PAH, we have used the B3LYP hybrid functional [46] combined with the 3-21G basis set [47] implemented in the Gaussian09 program [48] to simulate the Raman spectrum of a model soot particle. The Raman activities obtained in the calculations were converted to Raman intensities using the intensity theory of Raman scattering [49]. The calculated spectrum is complex, due to the high number of atoms present in the molecule. There is a total of 750 normal modes including 571 Raman active ones, yet only 32 modes have normalized intensities larger than 0.01 . The calculation provides at least one intense mode in the region of each band (except for the D4 band). Figure 7 presents a selection of the most intense vibrational modes located around the position of the experimental bands.

For the D1 region, we found two intense modes at 1281 and $1288 \mathrm{~cm}^{-1}$ corresponding to the breathing of the carbon rings [26], [34]; the most intense mode at $1281 \mathrm{~cm}^{-1}$ is shown Figure 7. As said before, these breathing modes are forbidden by symmetry in graphite, and are only observable when the symmetry is lowered, as it is the case in soot where the graphitic layers have finite sizes.

In the D2 band region, our calculations show an intense mode at $1604 \mathrm{~cm}^{-1}$ corresponding to a lattice mode similar to the $\mathrm{G}$ band, and a second mode at $1648 \mathrm{~cm}^{-1}$, corresponding to the $\mathrm{C}=\mathrm{C}$ stretching mode of carbon atoms at the edge (Figure 7), and more specifically to those present at the joint of two zigzag edges (Figure S2). The ratio of the calculated Raman activity of this later mode with the D1 mode at $1281 \mathrm{~cm}^{-1}$ is 0.077 , agreeing well with the ratio between the number of carbon atoms in the joints of zigzag edges and internal carbons (0.08). This mode related to edge carbon atoms is consistent with the 
experimental observation of Eckman et al. which linked the intensity of the D2 band with the formation of small crystalline domains of graphene due to an increasing number of vacancy defects [36].

The D3 band is usually assigned to amorphous carbon [38]-[40]. On the other hand, the calculations show four modes in the $1450-1550 \mathrm{~cm}^{-1}$ region. The two most intense ones are found at 1505 and $1526 \mathrm{~cm}^{-1}$, the first one corresponding to asymmetric breathing of the carbon rings (Figure 7), the second one corresponding to the C-C stretching of internal and edge carbons (not shown). HRTEM measurements do not show amorphous carbon in the soot samples analyzed. This seems to indicate that, in our case, the observed D3 band is linked to the internal vibrational modes of small graphitic domains rather than to amorphous carbon. In addition, the integrated area of D3 and D1 bands (normalized to G band) are correlated (Figure S3) whereas, in principle, a D3 band coming from amorphous carbon should not be linked to D1 band.

The C-C stretching mode corresponding to the $\mathrm{G}$ band is also found in the calculated spectrum at $1589 \mathrm{~cm}^{-1}$ as a double degenerated mode. We couldn't find any intense mode in the region of the D4 band. Thus the observed D4 band might be related to polyene-like stretching vibrations [40]-[42], not simulated with our PAH model.

\subsection{NEXAFS and XPS}

\subsubsection{Bulk NEXAFS (TEY)}

Figure 8 shows the carbon K-edge spectra recorded in total electron yield (probing the bulk of the soot) of the samples collected at $70 \%, 85 \%$ and $100 \% \mathrm{~F}_{00}$, compared to graphite HOPG. The pre-edge regions are set to zero and the spectra are normalized to their total integrated intensities. The NEXAFS spectrum of graphite presents a sharp peak at $285.5 \mathrm{eV}$ corresponding to the $\mathrm{C} 1 \mathrm{~s} \rightarrow \pi^{*}$ band excitation [50], overlying a first flat continuum of $\pi$ symmetry between $286 \mathrm{eV}$ and $291 \mathrm{eV}$ [51],[52]. A weak transition is also observed at 288 $\mathrm{eV}$. This transition corresponds to oxygenated species resulting from the contamination of HOPG surface by carbonyl or carboxyl groups [53],[54]. A second continuum of $\sigma$ symmetry starts above $291 \mathrm{eV}$, beginning with a sharp excitonic resonance at $291.8 \mathrm{eV}$ [55],[56] followed by a $\sigma^{*}$ transition at $292.9 \mathrm{eV}$, a shape resonance related to the electron singlescattering between two adjacent carbons in the graphite hexagons [50],[57]. The series of broad resonances above $295 \mathrm{eV}$ can be alternatively understood as excitations to high energy 
bands of the empty density of states (DOS) of graphite [50],[51] or as electron multiplescattering resonances within the carbon lattice of the graphene layer [58]. It is noteworthy that the NEXAFS spectrum of graphite is very close to that of substrate-decoupled graphene [59] and single-wall nanotubes [54], indicating that interlayer interactions have a negligible contribution in the spectrum of graphite.

The carbon K-edge spectra of the soot are very similar to each other, and present an overall shape close to that of HOPG. We observe a transition at $285.5 \mathrm{eV}$ common to all samples, which we assign to the $\mathrm{C} 1 \mathrm{~s} \rightarrow \pi^{*}$ excitation in the graphene layer. This transition is slightly asymmetrical on the low energy side. Above the $\pi^{*}$ transition, the flat continuum observed between 287 and $291 \mathrm{eV}$ is typical of graphite-like material, with weak transitions around $288 \mathrm{eV}$ due to oxidized species. The second threshold around $291 \mathrm{eV}$ is broader than in graphite, and the excitonic feature at $291.8 \mathrm{eV}$ is strongly damped. We also observe the remains of the $\sigma^{*}$ shape resonance around $293 \mathrm{eV}$. The overall slope of the continuum above $295 \mathrm{eV}$ is close to that of graphite, even though the multiple scattering resonances of graphite are not clearly observed.

Figure $8 b$ displays a fitted spectrum (engine operation regime $70 \% \mathrm{~F}_{00}$ ) in the $282-295$ $\mathrm{eV}$ energy range using a combination of Gaussian functions to model excitations to discrete states, and an arctangent function to model the $\pi$ threshold at $286 \mathrm{eV}$. The low energy side of the $\pi^{*}$ graphitic excitation is modeled by a transition at $284.7 \mathrm{eV}$. This transition (labelled $\pi^{*}($ edge $\left.)\right)$ is typical of nano-sized graphene sheets, and assigned to $\pi^{*}$ states related to carbon atoms located at the edge [60]-[66]. Such a shoulder has also been reported in ethylene soot [67],[68], diesel soot [69] and various carbonaceous minerals [70]-[72]. The intensity ratio $\mathrm{R}=$ $\pi^{*}($ edge $) / \pi^{*}$ graphitic decreases with the increase of the graphene size, and falls to zero both for graphite or for an infinite graphene layer [61],[64]. This ratio $\mathrm{R}=0.45,0.45$ and 0.47 for the $70 \%, 85 \%$ and $100 \% \mathrm{~F}_{00}$ samples respectively, is very close to $\mathrm{R}=0.44$ that corresponds to the ratio of carbon atoms located at the periphery over those located inside a graphene layer of $2.8 \mathrm{~nm}$. This result is consistent with the lateral extensions of carbonaceous layers measured in HRTEM and Raman spectroscopy. It is noteworthy that this $\pi^{*}$ shoulder at 284.7 $\mathrm{eV}$ has been alternatively assigned to quinoid functionalities [73]. As we will see later, in our case this is inconsistent with both the oxygen K-edge NEXAFS spectra assignments, and with the very weak oxygen contents measured by XPS that makes unlikely the presence of quinoid functionalities in the $\mathrm{C} 1 \mathrm{~s}$ spectra. 
The weak transitions between 286 and $289 \mathrm{eV}$ correspond to $\mathrm{C} 1 \mathrm{~s} \rightarrow \pi^{*}$ resonances in species containing carbonyl groups in different bonding environments, as phenolic/ketones $(286.5 \mathrm{eV})$, aliphatic/aromatic carbonyls $(287.5 \mathrm{eV})$ and acids/carboxyls at $288.3 \mathrm{eV}$ [53][55]. The excitonic feature at $291.8 \mathrm{eV}$ is strongly damped since it depends on the spatial extent of the 1s hole perturbation (about five bond lengths in graphite [75]), therefore sensitive to the small size of the crystallites. The spectral broadening around $291 \mathrm{eV}$ is well modeled by a Gaussian centered at $290 \mathrm{eV}$ (labelled $\sigma^{*}$ defects). Such broadening is also observed in the NEXAFS spectra of $\mathrm{Ar}^{+}$sputtered HOPG [52] and in nano-graphene units of activated carbon fibers [64], and is a consequence of structural defects within the graphene planes [52]. In accordance with the shape resonance model in NEXAFS spectroscopy [76], we can associate this resonance to a $\sigma^{*}$ transition relative to $\mathrm{C}-\mathrm{C}$ distances specific of these topological defects. The negative energy shift of $-2.9 \mathrm{eV}$ with respect to the normal position of the $\sigma^{*} \mathrm{C}-\mathrm{C}$ in graphite $(292.9 \mathrm{eV})$ indicates that these $\mathrm{C}-\mathrm{C}$ bonds are slightly elongated. Indeed, using the empirical correlation between $\sigma^{*} \mathrm{C}-\mathrm{C}$ energies and bond length [76], such shift can be associated to C-C distances of $0.146 \mathrm{~nm}(0.142 \mathrm{~nm}$ in graphite). Elongated C-C bonds around $0.145 \mathrm{~nm}$ are found in pentagon-heptagon topological defects [77], which have been experimentally observed on defective electron-irradiated graphene [78]. It has been recently shown through calculation that such defects will generate a density of empty states of $\sigma$ symmetry at $290 \mathrm{eV}$ related to the carbon atoms located within the heptagon [79], exactly as observed here. The carbon atoms located in the neighboring pentagons have $\mathrm{C}-\mathrm{C}$ distances shorter than graphite, around $0.138 \mathrm{~nm}$ [77], that should give rise to $\sigma^{*} \mathrm{C}-\mathrm{C}$ resonances this time slightly shifted above that of graphite [79], making it difficult to detect in the NEXAFS signal.

Figure $8 c$ presents the oxygen K-edge TEY NEXAFS spectra of the $70 \%, 85 \%$ and $100 \% \mathrm{~F}_{00}$ samples, compared to the reference electron energy loss spectra of benzoquinone [73], acetone ${ }^{1}$ and diisopropyl ether $\mathrm{C}_{6} \mathrm{H}_{14} \mathrm{O}$ [80] in the gas phase. Soot samples spectra have similar shapes for all three regimes. By comparison with the acetone spectrum, we can assign the peak at $530.8 \mathrm{eV}$ to $\mathrm{O} 1 \mathrm{~s} \rightarrow \pi^{*}$ transition of ketone/carbonyls groups. The weak feature at $534.5 \mathrm{eV}$ is assigned to $\mathrm{O} 1 \mathrm{~s} \rightarrow \pi^{*}$ transition of acid/carboxyls [54]. It is followed by a strong absorption dominated by a broad $\sigma^{*}$ resonance at $538.5 \mathrm{eV}$. Comparing to the spectrum of di-

${ }^{1}$ unpublished data; spectra from the COREX database http://unicorn.chemistry.mcmaster.ca/corex/alpha-list.html 
isopropyl ether, and anticipating the O1s XPS results presented in the next section, we can assign this feature to cyclic or linear ether-like C-O-C functionalities. The sharp O1s $\rightarrow \pi^{*}$ transition of benzoquinone at $529.7 \mathrm{eV}$ is hardly observed on the $\mathrm{O} 1 \mathrm{~s}$ spectra, which confirms that the strong shoulder at $284.7 \mathrm{eV}$ of the carbon K-edge cannot be due to quinoid groups.

\subsubsection{Surface NEXAFS (PEY)}

Figure $9 a$ compares the partial electron yield (PEY), only probing the surface, and the TEY (bulk) NEXAFS spectra at the carbon K-edge at $70 \%, 85 \%$ and $100 \% \mathrm{~F}_{00}$ regimes. The pre-edge regions are set to zero and the spectra are normalized to their integrated intensities. The overall shape of the PEY spectra is the same for the three engine operation regimes, but is consistently different from the bulk signals. The maximum of the $\mathrm{C} 1 \mathrm{~s} \rightarrow \pi^{*}$ excitation appears slightly shifted at lower energy. Instead of a flat $\pi^{*}$ graphite-like continuum between $287 \mathrm{eV}$ and $291 \mathrm{eV}$, we observe an increasing slope where transitions to oxidized species appear stronger than in the bulk. The second edge observed at $291 \mathrm{eV}$ in HOPG and for the bulk spectra of the soot samples (already broadened in TEY) is strongly blurred, and the $\sigma^{*}$ resonance at $292.9 \mathrm{eV}$ is broad and structureless. The slope of the continuum above $295 \mathrm{eV}$ is also significantly different from the bulk spectra.

The PEY spectra were deconvoluted using the same procedure that was applied to the TEY spectra; the results being mostly the same at all regimes, only the $70 \% F_{00}$ sample is presented in Figure 9b. Concerning the edge state at $284.7 \mathrm{eV}$, the intensity ratio $\mathrm{R}=$ $\pi^{*}($ edge $) / \pi^{*}$ graphitic is $0.51,0.43$ and 0.42 for the $70 \%, 85 \%$ and $100 \% \mathrm{~F}_{00}$ engine operating regimes, respectively, almost unchanged compared to the bulk values. This indicates that the graphene layers at the surface of the particles have the same average size as in the bulk. In Figure $9 b$ (bottom) the difference spectrum between the PEY and TEY is plotted, revealing features specific to the surface of the soot. Firstly, we observe an additional contribution at $284.9 \mathrm{eV}$. This corresponds to the $\mathrm{C} 1 \mathrm{~s} \rightarrow \pi^{*}$ excitation of $-\mathrm{C}=\mathrm{C}-$ functionalities [81], indicating the presence of unsaturated organic fragments at the surface and absent in the bulk. This organic phase can be understood as a snapshot of the end of the growth process of the graphene sheets, interrupted as the combustion process reached its end. One can estimate the relative amount of this organic phase adsorbed at the soot's surface by dividing the area of its fingerprint at $284.9 \mathrm{eV}$ with the sum of all the $\pi *$ carbon components (the edge contribution at $284.6 \mathrm{eV}$, the organic carbon at $284.9 \mathrm{eV}$ and the graphitic carbon at $285.4 \mathrm{eV}$ ). This gives an organic contribution of $30 \%, 17 \%$ and $22 \%$ for the $70 \%, 85 \%$ and $100 \% \mathrm{~F}_{00}$ samples, 
respectively. Secondly, the PEY-TEY difference signal shows a marked enhancement of the intensity between 287 and $291 \mathrm{eV}$, corresponding to increased concentrations of (1) the carbonyls functions in aliphatic/aromatic carbonyls $(287.5 \mathrm{eV})$ and acids/carboxyls at 288.3 $\mathrm{eV}$ (yet the carbonyls concentration in phenolic/ketones at $286.5 \mathrm{eV}$ has not changed compared to the bulk), and (2) an increase of the contribution of structural defects at $290 \mathrm{eV}$. The enhancement of the oxidation at the soot surface can be estimated from the ratio between the intensities of the transitions of the oxidized components measured on the PEY and the TEY spectra. We find values of $1.44,1.78$ and 1.43 for the $70 \%, 85 \%$ and $100 \% \mathrm{~F}_{00}$ regimes, respectively. For example, in the $85 \% \mathrm{~F}_{00}$ sample, these figures suggest that the oxidized species are $78 \%$ more abundant at the surface than in the bulk of the soot. Likewise, the concentration increase of structural defects at the surface can be estimated from the ratio of the transition intensity at $290 \mathrm{eV}$ measured in PEY and TEY, giving values of 1.7, 2.1 and 1.9 for the $70 \%, 85 \%$ and $100 \% \mathrm{~F}_{00}$ engine regime samples. The defect concentrations at the surface are then about twice those of the bulk.

\subsubsection{XPS}

The XPS spectra mainly show the carbon and oxygen lines, with some traces of sulfur detected at $163.4 \mathrm{eV}$ (S 2p levels, not presented), as also observed with EDX. This binding energy corresponds to sulfur (II) in organic thiophene or thiophenol, and to sulfur (IV) like in $\mathrm{SO}_{2}$ or sulfur (VI) in $\mathrm{H}_{2} \mathrm{SO}_{4}$. Using the Casa XPS tabulated relative sensitivity factors of 1 for $\mathrm{C} 1 \mathrm{~s}$ and 1.6 for $\mathrm{S} 2 \mathrm{p}$, we estimate the S/C ratio to be $1 \%, 0.4 \%$ and $0.5 \%$ for the $70 \%, 85 \%$ and $100 \% \mathrm{~F}_{00}$ samples, respectively. This is higher than what deduced from EDX $(<0.1 \%$ of the total atomic concentration). Yet, while EDX and XPS quantification are an order of magnitude different, one can say that sulfur remains as a trace element. XPS also allows quantifying the oxygen concentration relative to carbon, using the area ratio of the O1s and the $\mathrm{C} 1 \mathrm{~s}$ lines, given the RSF of carbon and oxygen calibrated experimentally, as explained in the experimental section. We find $\mathrm{O} / \mathrm{C}=2.3 \%, 1.7 \%$ and $3.5 \%$ for the $70 \%, 85 \%$ and $100 \%$ $F_{00}$ samples, respectively. Since the oxygen concentration is enhanced at the surface, as inferred from the difference between the NEXAFS PEY and TEY signals, the oxygen to carbon ratio in the bulk should be reduced accordingly. Dividing the O/C ratio obtained with XPS by the oxidation enhancement deduced from NEXAFS (see above), we find an O/C ratio in the bulk of $1.8 \%, 1 \%$ and $2.4 \%$ for the $70 \%, 85 \%$ and $100 \% \mathrm{~F}_{00}$ regimes, respectively. In this case the results are in good agreement with those deduced from $\operatorname{EDX}(\sim 3 \%)$. The oxygen abundance in the bulk and surface of the samples is therefore very low, and is lower in the 
bulk than at the surface. Figure 10a details the O1s XPS data for the three regimes. The O1s line is deconvoluted following the method proposed by Schuster et al. [82]. The component at $530.9 \mathrm{eV}$ is assigned to conjugated carbonyl, such as quinone groups. These functionalities have very weak intensity in the XPS signal, and so remain undetectable on the O1s NEXAFS spectrum at $529.7 \mathrm{eV}$, where their fingerprint is expected (Figure 8c). The XPS component at $532.1 \mathrm{eV}$ is assigned to non-conjugated carbonyl bonds, and is related in the $\mathrm{O} 1 \mathrm{~s}$ and $\mathrm{C} 1 \mathrm{~s}$ NEXAFS spectra to the $\mathrm{O} 1 \mathrm{~s} \rightarrow \pi^{*}$ transition at $530.8 \mathrm{eV}$ and the two $\mathrm{C} 1 \mathrm{~s} \rightarrow \pi^{*}$ transitions at 286.5 and $287.5 \mathrm{eV}$. The dominant XPS contribution at $533.3 \mathrm{eV}$ is assigned to $\mathrm{C}-\mathrm{O}$ single bonds, and is related on the O1s NEXAFS data to the broad O1s $\rightarrow \sigma^{*}(\mathrm{C}-\mathrm{O}-\mathrm{C})$ transition at $538.5 \mathrm{eV}$ that also dominates the NEXAFS spectra. The component at $534.7 \mathrm{eV}$ is assigned to hydroxyl groups. In carboxyl functions, the $\mathrm{OH}$ group leads to the $\mathrm{O} 1 \mathrm{~s} \rightarrow \pi^{*} \mathrm{NEXAFS}$ transition at $534.5 \mathrm{eV}$ and the $\mathrm{C} 1 \mathrm{~s} \rightarrow \pi^{*}$ transition at $288.3 \mathrm{eV}$ [83]. Traces of adsorbed water are also detected at $536.5 \mathrm{eV}$. The area of each XPS component over the total area of the O1s XPS line is plotted in Figure 10b. This provides the chemical speciation of the oxidized species at the surface of the soot samples. About $60 \%$ of the soot oxidation consists in ether functions $\mathrm{C}-\mathrm{O}-\mathrm{C}$, either simple or cyclic. 20-30 \% consists in carbonyl functions $\mathrm{C}=\mathrm{O}$, either as a ketone or a carboxyl. 5-9\% consists in $\mathrm{C}=\mathrm{O}$ groups conjugated with aromatic rings, specific to a quinoid structure. The remaining 5-9\% consists in hydroxyl C-OH groups. The C1s XPS data of the soot samples at the three regimes compared to HOPG are shown Figure 10c. Two main components are observed, one at $284.7 \mathrm{eV}$, corresponding to graphitic carbon, and one at $285.1 \mathrm{eV}$, labelled as "defects", corresponding to all the non-graphitic carbon contributions, such as carbon atoms at the edge of the graphene layers, polyene connected to the edges, or carbon in structural defects within the graphene layers. The oxidized functions, expected at $286.8 \mathrm{eV}$, weakly contribute to the $\mathrm{C} 1 \mathrm{~s}$ intensity due to the very low oxygen amount $(<3.5 \%)$. The graphitic peak in HOPG has been fitted using an asymmetric DoniachSunjic function modeling the inelastic loss of the photoelectron by interactions with the valence electrons and phonons. We have assumed that the graphitic component remains asymmetric in the soot samples, although it is broader $(F W M H=0.78 \mathrm{eV})$ than in HOPG $(F W M H=0.34 \mathrm{eV})$. The "defects" peak is modeled with a Gaussian function of FWMH $=1.1$ $\mathrm{eV}$. The ratio of the areas of the defect peak over the total peak area is $0.47,0.47$ and 0.42 for the $70 \%, 85 \%$ and $100 \% \mathrm{~F}_{00}$ samples, respectively. It is only 0.1 for HOPG, and these high non-graphitic ratios point out the very defective nature of the outer graphene layers of the soot primary particles. 


\section{Discussion}

Mostly spherical in shape and essentially made of carbon ( 97\% at.), soot primary particles exhibit a turbostratic structure, i.e. a stacking of few carbonaceous layers having small lateral extensions, with a random rotation angle between them, and concentrically oriented in space to form an onion-like structure. The interlayer spacing $d_{002}$ between carbonaceous layers is of about $0.36 \mathrm{~nm}$, independently of the engine operating regime. As it is larger than in graphite $\left(d_{002}=0.335 \mathrm{~nm}\right)$, it indicates that interactions between the carbonaceous sheets are weaker. Their lateral extension ranges from 2.54 to $3.66 \mathrm{~nm}$, which is much larger than values of $\sim 0.7 \mathrm{~nm}$ reported by Vander Wal et al. for soot particles emitted from a CFM-56-2 engine running with JP-8 fuel [11]. Although the engine operative regimes were similar in both studies we note that engines and fuels used were different, which complicates a direct comparison between values because of the influences of the engine technology on combustion conditions and therefore soot particle characteristics. It is however noteworthy to mention that lateral extension values obtained from HRTEM images in our study are consistent with those inferred from NEXAFS $(2.8 \mathrm{~nm})$ and Raman spectroscopy (2.67-3.06 nm) spectroscopies, and NEXAFS indicates that carbonaceous layers have the same lateral extensions at the surface and in the bulk of the particle. They are undoubtedly graphitic, as shown by the presence in the SAED patterns of reflections related to the $d_{100}$ and $d_{110}$ lattice spacing of graphite. Nevertheless, the soot SAED pattern is less defined than that of graphite. This is related to the stacked layers that are orientationally disordered, which is intrinsic to a turbostratic/onion-like structure. The C-C distances within the graphene sheets determined from SAED patterns is of about $0.14 \mathrm{~nm}$, which is slightly shorter than in graphite $(0.142 \mathrm{~nm})$ but is in agreement with values established for graphene nanocrystallites [84]. The $\mathrm{G}$ band in the Raman spectra indicates the presence of crystalline graphite, though it only represents $10 \%$ of the total integrated area for the first order Raman band of the soot samples analyzed. D1 and D2 bands result from the limited size of the layers, which allows their observation, forbidden by symmetry in infinite graphite plans. We also show how D3 band, traditionally assigned to amorphous carbon, can also be linked to the presence of small graphitic domains. These three bands represent the major contribution to the observed Raman band. Likewise, C1s NEXAFS spectra are also very close to graphite, although blurred and less structured, which we assume to be related to the limited length of the layers and their defective nature. The broadening of the Raman spectra is also likely related to such structural disorder. 
This study provides information on these defects. (1) Firstly, NEXAFS shows that there are edge defects that are inherent to the finite size of graphene layers. They produce a specific density of electronic state at the Fermi level, just above the main $\pi^{*}$ graphitic band. These edge atoms also allow the observation of the D1 band at $1350 \mathrm{~cm}^{-1}$, Raman inactive in the case of infinite graphitic planes, and the appearance of D2 band, directly linked to edge carbon as shown by the quantum chemical calculations. It is likely that some connection between the graphene plans occur at these edges through organic cycles or unsaturated chains, to which we assign the Raman D4 band. (2) Secondly, NEXAFS shows a strong feature at $290 \mathrm{eV}$ which we relate to heptagon-pentagon defects that may naturally occur during the growth of the particles. These defects also rise up out of the graphene sheet [85], which may facilitate the bending of the graphene layer (and tortuosity) observed with HRTEM. The defect concentration is about twice on the surface compared to the bulk, indicating that the last steps of the combustion reactions leave the surface very defective. At the side of these surface defects, high amounts of unsaturated organic hydrocarbons are detected with surface NEXAFS. They are absent in the bulk and only found at the surface of the soot, with concentrations ranging from $17 \%$ to $30 \%$ with respect to total carbon amount. We cannot rule out the existence of other kinds of defects that do not give specific signatures in spectra. The large contribution observed on C1s XPS spectra and labeled as "defects" peak, probably contains a large variety of carbonaceous point defects, including the heptagon-pentagon defects and the unsaturated organic hydrocarbons detected with surface NEXAFS. (3) Thirdly, NEXAFS and XPS allow the quantification and the identification of chemical defects, namely the oxide and sulfur functions. The bulk of the soot is poorly oxidized, at most $\mathrm{C} / \mathrm{O}=3.5 \%$ for the $100 \% \mathrm{~F}_{00}$ engine regime, the surface being $44 \%$ to $78 \%$ more oxidized than the bulk. This enhancement may be due to the higher concentration of structural defects, allowing more reactivity towards oxygen, during or after combustion. XPS and NEXAFS show that most of the oxidation is in the form of ethers (50-60\%), then in carbonyls (20-30\%), the rest being hydroxyls and conjugated carbonyls (e.g. quinones). EDX and NEXAFS allow for the detection of trace amounts of sulfur $(<1 \%)$ whereas XPS shows the presence of sulfur (II) in organic thiophene or thiophenol, and/or sulfur (IV) like in $\mathrm{SO}_{2}$ or sulfur (VI) like in $\mathrm{H}_{2} \mathrm{SO}_{4}$.

Figure 11 presents a schematic representation of the bulk (a) and surface (b) graphene layers, illustrating our findings. These molecular structures have been drawn and optimized with HyperChem ${ }^{\mathrm{TM}}$, using molecular classical mechanics calculations with a $\mathrm{MM}+$ force field. They respect the size of the graphene layers, the $\mathrm{O} / \mathrm{C}$ and $\mathrm{S} / \mathrm{C}$ ratios, the oxidation 
ratios, the defect enhancement between the surface and the bulk, and also account for the presence of $30 \%$ carbon atoms in unsaturated organic hydrocarbons at the surface. The ability of such surface to attract water molecules might be very different from that of graphite. There are many chemical defects, some with neutral or hydrophobic characters, like unsaturated organics, and some with hydrophilic character such as hydroxyls and ketones. Our preliminary molecular dynamic simulations also show that the heptagon-pentagon defects are hydrophilic. All these hydrophilic sites may allow effective condensation of water molecules, above the thermodynamic equilibrium conditions for condensation, lowering the onset temperature and saturation pressure for heterogeneous nucleation of ice on the soot surface, therefore favoring formation of contrails.

\section{Conclusion}

HRTEM, EDX, Raman spectroscopy, NEXAFS and XPS were used to study aircraft soot particles collected at the exhaust of a modern turbofan engine (PowerJet, SaM146-1S17) burning JET A-1 fuel at different engine operating regimes typical of the LTO cycle. This set of techniques allows for the description of some important physical and chemical properties of the soot primary particles, which we found not to vary significantly with the engine operating regimes. These particles are mainly composed of carbon ( 97\% at.), with a nanostructure made of concentrically arranged graphitic layers having small lateral extensions which range from 2.54 to $3.66 \mathrm{~nm}$. They are poorly oxidized (<3\% at.), with a slight enhancement of the oxidation rate at the very surface. Oxide functions are essentially ketones and carbonyls, with few hydroxyls and quinones. Traces of sulfur II, IV or VI are also detected. The soot surface is mostly made of graphene layers of the same size as in the bulk, although more defective. It also presents a high concentration of unsaturated organic hydrocarbons that are not detected in the bulk.

\section{Acknowledgements}

This work was supported by the MERMOSE project for the characterization of emissions by aircraft engines and sponsored by DGAC (French national funds; see http://sites.onera.fr/MERMOSE/en). I.K.O., B. C., Y. C. and C. F. acknowledge the support of the CaPPA project (Chemical and Physical Properties of the Atmosphere), funded by the French National Research Agency (ANR) through the PIA (Programme d'Investissement 
d'Avenir) under contract ANR-11-LABX-0005-01 and by the Nord - Pas de Calais Regional Council and the European Funds for Regional Economic Development (FEDER). D. F., C. L, I. $\mathrm{M}$ and $\mathrm{Ph}$. P. wish to acknowledge 65e CPCFQ and PICS-CNRS N ${ }^{\circ} 6212$ for support. Some of the research described in this paper was performed at the Canadian Light Source, which is supported by the Canada Foundation for Innovation, Natural Sciences and Engineering Research Council of Canada, the University of Saskatchewan, the Government of Saskatchewan, Western Economic Diversification Canada, the National Research Council Canada, and the Canadian Institutes of Health Research. 


\section{References}

[1] Masiol M, Harrison R M. Aircraft engine exhaust emissions and other airport-related contribution to ambient air pollution: a review. Atmos. Environ. 2014;95:409-455.

[2] Lee DS, Fahey DW, Forster PM, et al. Aviation and global climate change in the $21 \mathrm{st}$ century. Atmos Environ. 2009;43(22-23):3520-3537.

[3] Myhre G, Samset BH, Schulz M, et al. Radiative forcing of the direct aerosol effect from AeroCom Phase II simulations. Atmos Chem Phys. 2013;13(4):1853-1877.

[4] Hendricks J, Kärcher B, Lohmann U. Effects of ice nuclei on cirrus clouds in a global climate model. J Geophys Res Atmos. 2011;116(18):1-24.

[5] Hoose C, Möhler O. Heterogeneous ice nucleation on atmospheric aerosols: a review of results from laboratory experiments. Atmos. Chem. Phys. 2012;12:9817-9854.

[6] Petzold A, Ström J, Schröder FP, Kärcher B. Carbonaceous aerosol in jet engine exhaust: emission characteristics and implications for heterogeneous chemical reactions. Atmos. Environ. 1999;33:2689-2698.

[7] Braun A. Carbon speciation in airborne particulate matter with C (1s) NEXAFS spectroscopy. J. Environ. Monitor. 2005;7(11):1059-1065.

[8] Timko MT, Yu Z, Onasch TB, Wong HW, Miake-Lye RC, Beyersdorf AJ, Anderson BE, Thornhill KL, Winstead EL, Corporan E, DeWitt MJ, Klingshirn CD, Wey C, Tacina K, Liscinsky DS, Howard R, Bhargava A. Particulate emissions of gas turbine engine combustion of a Fischer-Tropsch synthetic fuel. Energy Fuels 2010;24:5883-5896.

[9] Kinsey JS, Hays MD, Dong Y, Williams DC, Logan R. Chemical characterization of the fine particle emissions from commercial aircraft engines during the Aircraft Particle Emissions eXperiment (APEX) 1 to 3. Environ. Sci. Technol. 2011;45:3415-3421.

[10] Lobo P, Rye L, Williams PI , Christie S, Uryga-Bugajska I, Wilson CW, Hagen DE, Whitefield PD, Blakey S, Coe H, Raper D, Pourkashanian M. Impact of alternative fuel on emission characteristics of a gas turbine engine - Part 1: gaseous and particulate matter emissions. Environ.Sci. Technol. 2012;46:10805-10811.

[11] Vander Wal RL, Bryg VM, Huang CH. Aircraft engine particulate matter: macro- microand nanostructure by HRTEM and chemistry by XPS. Combust. Flame 2014;161:602-611. 
[12] Popovicheva OB, Persiantseva NM, Trukhin ME, Rulev GB, Shonija NK, Buriko YY, Starik AM, Demirdjian B, Ferry D and Suzanne J. Experimental characterization of aircraft combustor soot: microstructure, surface area, porosity and water adsorption. Phys. Chem. Chem. Phys. 2000;2:4421-4426.

[13] Mazaheri M, Bostrom, TE, Johnson, GR, Morawska, L. Composition and morphology of particle emissions from in-use aircraft during takeoff and landing. Environ. Sci. Technol. 2013;47:5235-5242.

[14] International Civil Aviation Organization. Environmental Protection: International Standards and Recommended Practices - Annex 16 to the Convention on International Civil Aviation, 2008, 3rd ed., Vol.II, Aircraft Engine Emissions, Montreal, QC, Canada

[15] Schneider CA, Rasband WS, Eliceiri KW. NIH Image to ImageJ: 25 years of image analysis. Nature Methods 2012;9:671-675.

[16] Lapuerta M, Oliva F, Agudelo JR, Stitt JP. Optimization of Raman Spectroscopy Parameters for Characterizing Soot from Different Diesel Fuels. Combust. Sci. Technol. 2011,183(11):1203-1220.

[17] Lesiak B, Jablonski A, Prussak Z, Mrozek P. Experimental determination of the inelastic mean free path of electrons in solids method. Surf. Sci. 1989;223:213-232.

[18] Stöhr J. NEXAFS spectroscopy. Berlin:Springer-Verlag. 1992:122-130.

[19] Tanuma S, Powell CJ, Penn DR. Calculations of Electron Inelastic Mean Free Paths II. Data for 27 Elements over the 50-2000 eV Range. Surf. Interface Anal. 1991;17:911-926.

[20] Liati A, Brem BT, Durdina L, Vögtli M, Rojas Dasilva YA, Dimopoulos Eggenschwiler P, Wang J. Electron microscopic study of soot particulate matter emissions from aircraft turbine engines. Environ. Sci. Technol. 2014;48:10975-10983.

[21] Buseck PR, Adachi K, Gelencsér A, Tompa E, Pósfai M. Ns-soot: a material-based term for strongly light-absorbing carbonaceous particles. Aerosol Sci. Technol. 2014;48:777-788.

[22] Rouzaud JN, Oberlin A, Beny-Bassez C. Carbon films: structure and microtexture (optical and electron microscopy, Raman spectroscopy). Thin Solid Films 1983;105:75-96.

[23] Raman microspectroscopy characterization of carbon blacks: spectral analysis and structural information. Carbon 2015;84:479-490. 
[24] Vander Wal RL, Bryg VM, Hays MD. Fingerprinting soot (towards source identification): physical structure and chemical composition. Aerosol Sci. 2010;41:108-117.

[25] Kovács Kis V, Pósfai M, Lábár JL. Nanostructure of atmospheric soot particles. Atmos. Environ. 2006;40:5533-5542.

[26] Sadezky A, Muckenhuber H, Grothe H, Niessner R, Pöschl U. Raman microspectroscopy of soot and related carbonaceous materials: spectral analysis and structural information. Carbon 2005;43:1731-42.

[27] Catelani T., Pratesi G, Zoppi M. Raman Characterization of ambient airborne soot and associated mineral phases. Aerosol Sci. Tech. 2014;48:13-21.

[28] Lahfid A, Beyssac O, Deville E, Negro F, Chopin C, Goffé b. Evolution of the Raman spectrum of carbonaceous meterial in low-grade metasediments of the Glarus Alps (Switzerland).Terra Nova. 2010;22:324-60.

[29] Lunsdorf NK, Dunkl I, Schmidt BC, Rantitsch G. Eynatten H. Towards a higher comparability of Geothermometric data obtained by Raman spectroscopy of carbonaceous material. Part I: Evaluation of biasing factors. Geostand. Geoanal. Res.. 2014;38:73-94.

[30] Sheng C. Char structure characterised by Raman spectroscopy and its correlations with combustion reactivity. Fuel. 2007;86:2316-24.

[31] Carpentier Y, Féraud G, Dartois E, Brunetto R, Charon E, Cao AT, d'Hendecourt L, Brechignac Ph,Rouzaud JN,Pino T. Nanostructuration of carbonaceous dust as seen through the positions of the 6.2 and 7.7 $\mu \mathrm{m}$ AIBs. Astron. Astrophys. 2012;548:A40.

[32] Schmid J., Grob, B., Neissner, R, Ivleva, P. Multi-wavelength Raman microscopy for rapid prediction of soot oxidation reactivity. Anal. Chem. 2010;83:1173-1179.

[33] Ivleva NP, McKeon U, Niessner R, Poschl U. Raman microspectroscopic analysis of size-resolved atmospheric aerosol particle samples collected with an ELPI: Soot, humic-like substances, and inorganic compounds. Aerosol Sci. Tech. 2007;41(7):655-671.

[34] Di Donato E, Tommasini T, Fustella G, Brambilla L, Castiglioni C, Zerbi G, et al. Wavelength-dependent Raman activity of D2h symmetry polycyclic aromatic hydrocarbons in the D-band and acoustic phonon regions. Chem. Phys. 2004;301:81-93. 
[35] Katagiri G, Ishida H, Ishitani A. Raman spectra of graphite edge planes. Carbon 1988;26:565-571.

[36] Eckman A, Felten A, Mischenko A, Britnell L, Krupke R, Novoselov KS, Casiraghi C. Probing the nature of defects in graphene by Raman Spectroscopy. Nano Lett. 2012;12:39253930.

[37] Dresselhaus MS, Dresselhaus G. Topics in applied physics, vol. 51. Berlin: SpringerVerlag, 1982. p. 3-57.

[38] Cuesta A, Dhamelincourt P, Laureyns J, Martinez-Alonso A, Tascon JMD. Raman microprobe studies on carbon materials. Carbon 1994;32:1523-1532.

[39] Jawhari T, Roid A, Casado J. Raman spectroscopic characterization of some commercially available carbon black materials. Carbon 1995;33:1561-1565.

[40] (a) Dippel B, Jander H, Heintzenberg J. NIR FT Raman spectroscopic study of flame soot. Phys Chem Chem Phys 1999;1:4707-12. (b) Dippel B, Heintzenberg J. Soot characterization in atmospheric particles from different sources by NIR FT Raman spectroscopy. J Aerosol Sci 1999;30(Suppl.1):907-908.

[41] Livneh T, Bar-Ziv E, Salatino P, Senneca O. Evolution of reactivity of highly porous chars from Raman microscopy. Combust Sci. Technol 2000;153:65-82.

[42] Bar-Ziv E, Zaida A, Salatino P, Senneca O. Diagnostics of carbon gasification by Raman microprobe spectroscopy. P. Combust. Inst. 2000;28:2369-2374.

[43] Zaida V, Bar-Ziv E, Radovic LR, Lee Y-J. Further development of Raman microprobe spectroscopy for characterization of char reactivity. P. Combust. Inst. 2006;31:1873-1880.

[44] Cançado LG, Takai, K., Enoki, T., Endo, M., Kim, Y. A., Mizusaki, H., Jorio, A., Coelho, LN., Magalhães-Paniago, R., Pimenta, MA. General equation for the determination of the crystallite size La of nanographite by Raman spectroscopy, Appl. Phys. Lett. 2006;88(16):163106.

[45] Negri F, Di Donato E, Tommasini M, Castiglioni C, Zerbi G, Müllen K. Resonance Raman contribution to the D band of carbon materials: Modeling defects with quantum chemistry. J. Chem. Phys. 2004;120:11889.

[46] Becke, AD. Density-functional thermochemistry. III. The role of exact exchange. J. Chem. Phys. 1993;98:5648-5652. 
[47] Binkley JS, Pople JA, Hehre WJ. Self-Consistent Molecular Orbital Methods. 21. Small Split-Valence Basis Sets for First-Row Elements. J. Am. Chem. Soc., 1980;102:939-947.

[48] Frisch MJ, Trucks GW, Schlegel HB, Scuseria GE, Robb MA, Cheeseman, JR, et al. Gaussian 09, Revision B01, Gaussian, Inc., Wallingford CT, 2009.

[49] Polavarapu PL. Ab initio vibrational Raman and Raman optical activity spectra. J. Phys. Chem. 1990;94:8106-8112

[50] Rosenberg RA, Love PJ, Rehn V. Polarization-dependent C(K) near-edge-absorption fine structure of graphite. Phys. Rev. B. 1986;33(6):4034-4037.

[51] Mane JM, Le Normand F, Medjo RE, Cojocaru CS, Ersen O, Senger A, Laffon C, Thiodjio BT, Biouele CM, Ben-Bolie GH, Ateba PO, Parent P. Alignment of Vertically Grown Carbon Nanostructures Studied by X-Ray Absorption Spectroscopy. Materials Sciences and Applications. 2014;5:966-983.

[52] Gago R, Jiménez I, Albella JM. Detecting with X-ray absorption spectroscopy the modification $s$ of the bonding structure of graphitic carbon by amorphisation, hydrogenation and nitrogenation. Surf. Sci. 2001;482-485:530-536.

[53] Urquhart SG, Ade H. Trends in the carbonyl core $(\mathrm{C} 1 \mathrm{~s}, \mathrm{O} 1 \mathrm{~s}) \rightarrow \mathrm{p} *(\mathrm{C}=\mathrm{O})$ transition in the near-edge absorption fine structure spectra of organic molecules. J. Phys. Chem. B. 2002;106:8531-8538.

[54] Leon V, Parret R, Almairac R, Alvarez L, Babaa M-R, Doyle BP, Ienny P, Parent P, Zahab A, Bantignies J-L. Spectroscopic study of double-walled carbon nanotube functionalization for preparation of carbon nanotube/epoxy composites. Carbon 2012;50:4987-4994.

[55] Brühwiler PA, Maxwell AJ, Puglia C, Nilsson A, Andersson S, Mårtensson N. $\pi^{*}$ and $\sigma^{*}$ excitons in C1s absorption of graphite. Phys. Rev. Lett. 1995;74(4):614-617.

[56] Wessely O, Katsnelson MI, Eriksson O. Theory of Dynamical Core-Hole Screening in Graphite from X-Ray Absorption Spectra. Phys. Rev. Lett. 2005;94(16):167401.

[57] Ågren H, Vahtras O, Carravetta V. Near-edge core photoabsorption in polyacenes: model molecules for graphite. Chem. Phys.1995;196( 1-2):47-58. 
[58] Zou Y, Tang JC. Multiple scattering approaches to carbon K-shell near-edge x-ray absorption fine structure of graphite. J. Phys.:Condens. Matter. 1994;6:2949-2956.

[59] Voloshina EN, Generalov A, Weser M, Böttcher S, Horn K, Dedkov YS. Structural and electronic properties of the graphene/Al/Ni(111) intercalation system. New Journal of Physics. 2011;13:113028-113046.

[60] Nakada K, Fujita M, Dresselhaus G, Dresselhaus, MS, Edge state in graphene ribbons: nanometer size effect and edge shape resonance. Phys. Rev. B. 1996;54(24):17954-17961.

[61] Entani S, Ikeda S, Kiguchi M, Saiki K, Yoshikawa G, Nakai I, Kondoh H, Ohta T. Growth of nanographite on Pt(111) and its edge state. Appl. Phys. Lett. 2006;88:153126.

[62] Enoki T, Takai K. The edge state of nanographene and the magnetism of the edge-state spins. Solid State Commun. 2009;149:1144-1150.

[63] Suenaga K, Masanori K. Atom-by atom spectroscopy at graphene edge. Nature. 2010;468:1088-1090.

[64] Kiguchi M, Takai K, Joly J, Enoki T, Sumii R, Amemiya K. Magnetic edge state and dangling bond state of nanographene in activated carbon fibers. Phys. Rev. B. 2011;84:045421.

[65] Velez-Fort E, Silly MG, Belkhou R, Shukla A, Sirotti F, Ouerghi Z. Edge state in epitaxial nanographene on 3C-SiC(100)/Si(100) substrate. Appl. Phys. Lett. 2013;103:083101.

[66] Hao SJ, Joly VLJ, Kaneko S, Takashiro JI, Takai K, Hayashi H, Enoki T, Kiguchi M. Magnetic edge-states in nanographene, $\mathrm{HNO}_{3}$-doped nanographen and its residue compounds of nanographene-based nanoporous carbon. Phys. Chem. Chem. Phys. 2014;16:6273-6282.

[67] Di Stasio S, Braun A. Comparative NEXAFS Study on Soot Obtained from an Ethylene/Air Flame, a Diesel Engine, and Graphite. Energ. Fuel. 2006:20;187-194.

[68] Hopkins R, Tivanski AV, Marten BD, Gilles MK. Chemical bonding and structure of black carbon reference materials and individual carbonaceous atmospheric aerosols. J. Aerosol Sci.2007;38:573-581. 
[69] Braun A, Mun BS, Huggins FE, Huffman GP. Carbon speciation of diesel exhaust and urban particulate matter NIST standard reference materials with C1s NEXAFS spectroscopy. Environ. Sci. Technol. 2007;41:173-178.

[70] Cody GD, Ade H, Wirick S, Mitchell GD, Davis A. determination of chemical-structural changes in vitrine accompanying luminescence alteration using C-NEXAFS analysis. Org. Geochem. 1998;28:441-455.

[71] Haberstroh PR, Brandes JA, Gelinas Y, Dickens AF, Wirick S, Cody G. Chemical composition of the graphitic black carbon fraction in riverine and marine sediments at submicron scales using carbon X-ray spectromicroscopy. Geochim. Cosmochim. Acta.2006;70:1483-1494.

[72] Solomon D, Lehman J, Wang J, Kinyangi J, Heymann K, Lu Y, wirick S, Jacobsen C. Micro- and nano-environments of $\mathrm{C}$ sequestration in soil: A multi-elemental STXMNEXAFS assessment of black $\mathrm{C}$ and organomineral associations. Sci. Total Environ. 2012;438:372-388.

[73] Francis JT, Hitchcock AP. Inner-shell spectroscopy of parabenzoquinone, hydroquinone, and phenol: distinguishing quinoid and benzenoid structures. J Phys. Chem. 1992;96:65986610.

[74] Hopkins RJ, Tivanski A V., Marten BD, Gilles MK. Chemical bonding and structure of black carbon reference materials and individual carbonaceous atmospheric aerosols. J Aerosol Sci. 2007;38(6):573-591.

[75] Ahuja R, Brühwiler PA, Wills JM, Johansson B, Mårtensson N, Eriksson O. Theroetical and experimental study of the graphite $1 \mathrm{~s}$ x-ray absorption edges. Phys. Rev. B. 1996;54(20):14396-14404.

[76] Stöhr J, Sette F, Johnson AL. Near-edge X-ray absorption fine-structure studies of chemisorbed hydrocarbons; bond length with a ruler. Phys. Rev. Lett. 1984;53(17):1684-1687.

[77] Leyssale JM, Vignoles GL, Villesuzanne A. Rippled nanocarbons from periodic arrangements of reordered bivacancies in graphene or SWCNTs. J. Chem. Phys. 2012;136(12):124705. 
[78] Hashimoto A, Suenaga K, Gloter A, Urita K, Iijima S. Direct evidence for atomic defects in graphene layers. Nature.2004;430(7002):870-873.

[79] Ehlert C, Unger WES, Saalfrank P. C K-edge NEXAFS spectra of graphene with physical and chemical defects: a study based on density functional theory. Phys. Chem. Chem. Phys. 2014;16:14083-14095.

[80] Urquhart SG, Hitchcock PA, Leapman RD, Priester RD, Rightor EG. Analysis of Polyurethanes Using Core Excitation Spectroscopy. Part II: Inner Shell Spectra of Ether, Urea and Carbamate Model Compounds. J. Pol. Sci. B. Pol. Phys.1995;33:1603-1620.

[81] Hitchcock AP, Beaulieu S, Steel T, Stöhr J, Sette F. Carbon K-Shell Electron Energy Loss Spectra of 1- and 2-Butenes, trans-1,3-Butadiene and Perfluoro-2-Butene. J. Chem. Phys. 1984;80:3927-3935.

[82] Schuster ME, Hävecker M, Arrigo R, Blume R, Knauer M, Ivleva NP, Su DS, Niessner R, Schlögl R. Surface Sensitive Study To Determine the Reactivity of Soot with the focus on the European Emission Standards IV and VI. J. Phys. Chem. A. 2011;115:2568-2580.

[83]Leon, V., Parret, R., Almairac, R., Alvarez, L., Babaa, M.-R., Doyle, B.P., Ienny, P., Parent, P., Zahab, A., Bantignies, J.-L. Spectroscopic study of double-walled carbon nanotubes functionalization for preparation of carbon nanotube / epoxy composites, Carbon 2012;50:4987-4994.

[84] Belenkov EA. Formation of Graphite Structure in Carbon Crystallites. Inorg. Mat. 2001; 37(9):928-934.

[85] Lusk MT, Carr LD. Nanoengineering defect structures on graphene. Phys. Rev. Lett. 2008;100(17):1-4. 


\section{Figure captions}

Figure 1. Soot particles nanostructure with increasing engine operating regimes.

Figure 2. Quantification of the HRTEM images for carbonaceous layers length evolution with increasing engine operating regimes.

Figure 3. EDX spectra from analyses of soot aggregates emitted at different engine operating regimes. $\mathrm{Cu}$ and $\mathrm{Si}$ are from the TEM grid.

Figure 4. Typical diffractogram of soot aggregates, (a) emitted at $70 \%$ engine operating regimes. (b) Integrated intensity radial profile of (a) and position of the (002), (100) and (110) reflections in the reciprocal space.

Figure 5. (a) Schematic representation of a turbostratic structure of carbon layers with random rotation angles $\theta_{1}$ and $\theta_{2}$. (b) Lattice spacing $d_{002}, d_{100}$ and $d_{110}$ giving rise to the SAED pattern.

Figure 6. (a). Typical Raman spectra obtained for the samples corresponding to $30 \%, 70 \%$, $85 \%$ and $100 \% \mathrm{~F}_{00}$ engine operating regimes. (b) Integrated band areas for each fitted band normalized to the total area. Error bars correspond to the standard deviation of the values obtained for different points within the same sample. Green, blue, purple, and orange bars correspond to the $30 \%, 70 \%, 85 \%$, and $100 \% \mathrm{~F}_{00}$ engine operating regimes, respectively.

Figure 7. Selected vibrational modes. The Raman normalized intensity and Raman shift $(\gamma)$ are shown for each mode. Arrows indicate the most significant vibrational motions of the carbon atoms.

Figure 8. (a) Carbon K-edge NEXAFS spectra recorded in TEY (bulk signal) of the soot samples collected at $70 \%, 85 \%$ and $100 \% \mathrm{~F}_{00}$ engine operating regimes, compared to graphite HOPG. The data are shifted for display. (b) Deconvolution of the $282-295 \mathrm{eV}$ region exemplified on the $70 \% \mathrm{~F}_{00}$ engine operating regime (see text); black line: fit to the data. (c) Oxygen K-edge NEXAFS spectra recorded in TEY at the three regimes, compared with benzoquinone, acetone and diisopropyl ether for assignment purpose (see text). The data are shifted for display. 
Figure 9. (a) Carbon K-edge NEXAFS spectra recorded in PEY (surface signal) of the soot samples collected at $70 \%, 85 \%$ and $100 \% \mathrm{~F}_{00}$ engine operating regimes, compared to the TEY spectra (bulk signal). The data are shifted for display. (b) Deconvolution (top) and PEYTEY difference (bottom) of the 282-295 eV region exemplified for the $70 \% \mathrm{~F}_{00}$ engine operating regime; black line: fit to the data.

Figure 10. (a) O1s XPS of the soot samples collected at $70 \%, 85 \%$ and $100 \% \mathrm{~F}_{00}$ regimes, with deconvolution in Gaussian components related to oxidized functionalities indicated on the figure. (b) Contribution of each component in the total O1s intensity (in \%). (c) C1s XPS of the soot samples collected at $70 \%, 85 \%$ and $100 \% \mathrm{~F}_{00}$ engine operating regimes compared to HOPG, with deconvolution in Gaussian components related to carbon in graphitic and defective environments.

Figure 11. Schematic representation of the graphene layers (top and side views); carbon is in blue, hydrogen in white, oxygen in red, sulfur in yellow. (a) Bulk layers are mostly graphitic of around $2.7 \mathrm{~nm}$ in length, with few topological defects such as heptagon-pentagons. Some oxidized groups ( $<2 \%$ at.) and traces of sulfur $(<1 \%$ at.) are detected. (b) Surface layers are about the same size as those found in the bulk, with twice as much topological defects. In addition, around $30 \%$ of carbon atoms are located in unsaturated organic hydrocarbons; the surface is also more oxidized than the bulk (3\% at.). 

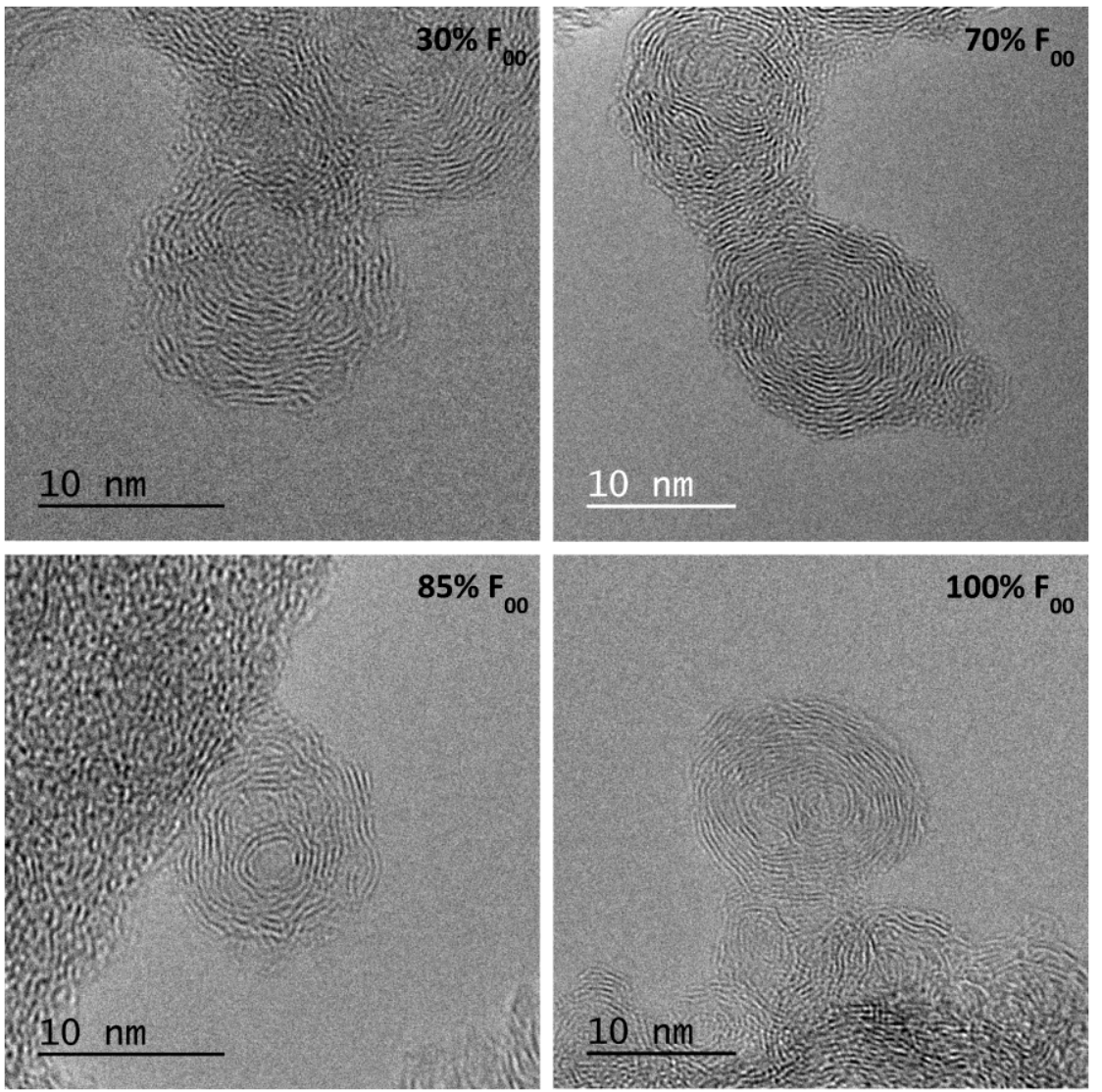

Figure 1. Soot particles nanostructure with increasing engine operating regimes. 

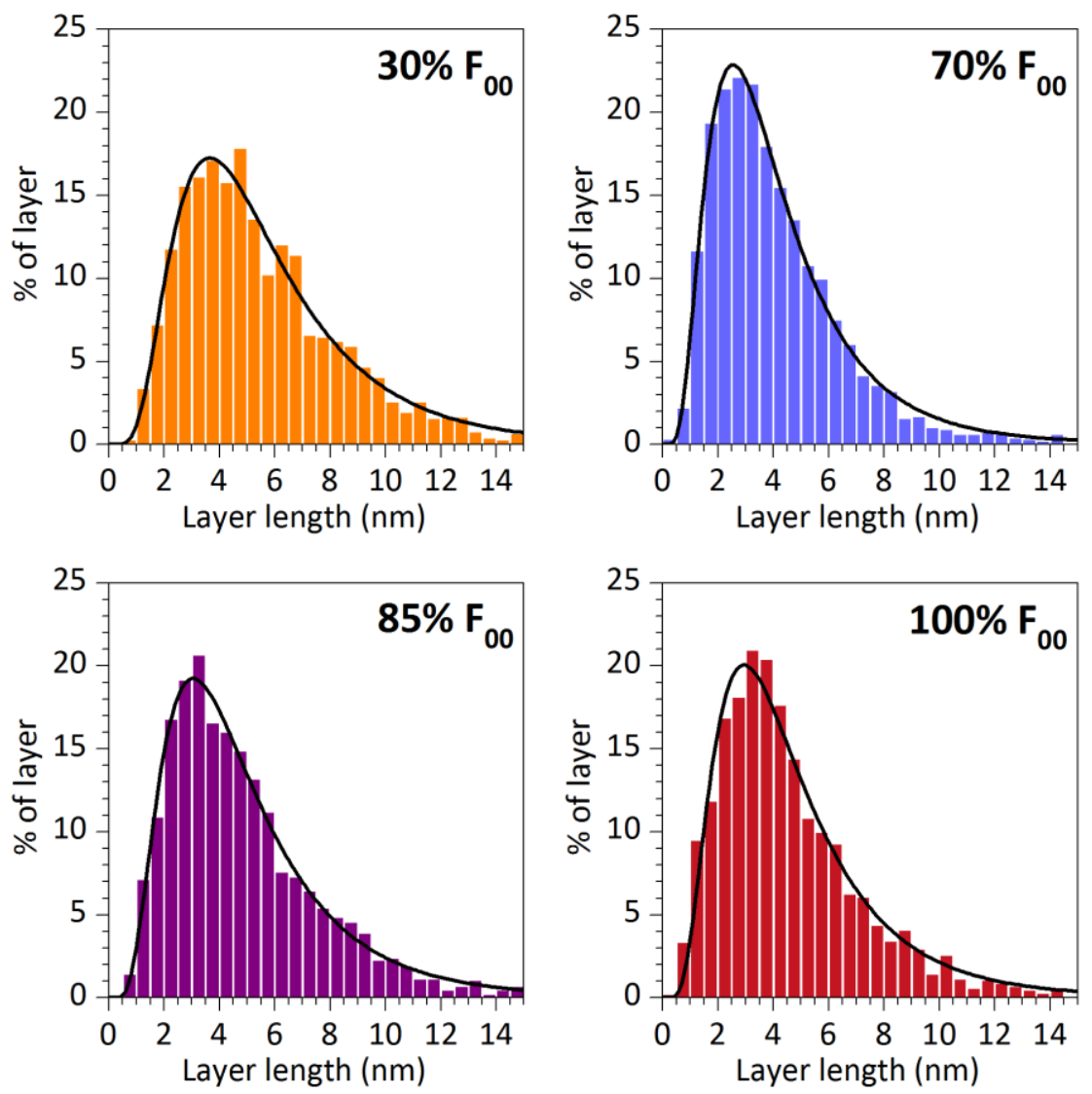

Figure 2. Quantification of the HRTEM images for carbonaceous layers length evolution with increasing engine operating regimes. 

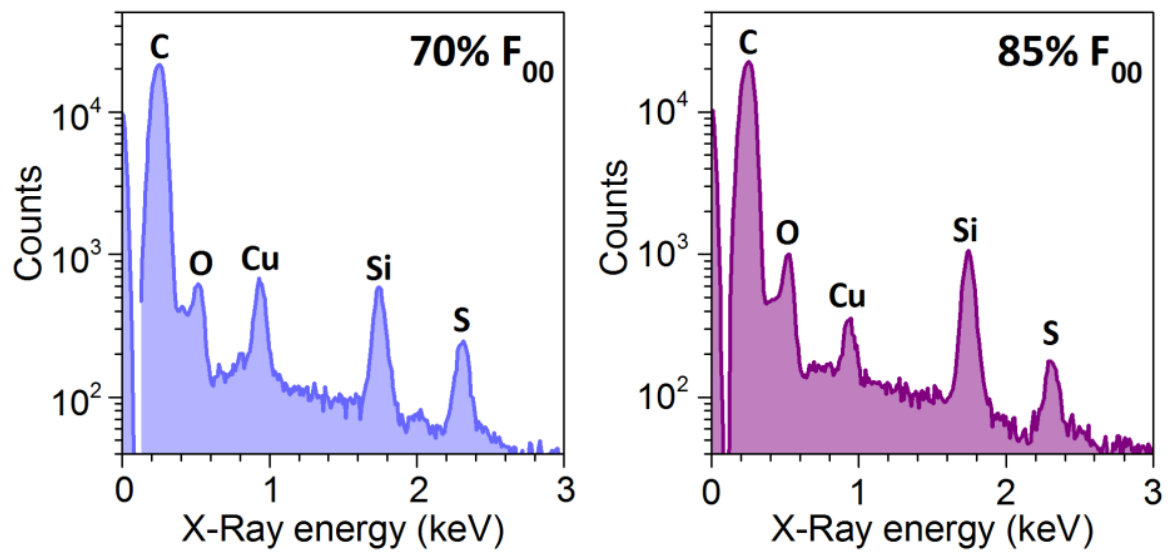

Figure 3. EDX spectra from analyses of soot aggregates emitted at different engine operating regimes. $\mathrm{CU}$ and Si are from the TEM grid. 

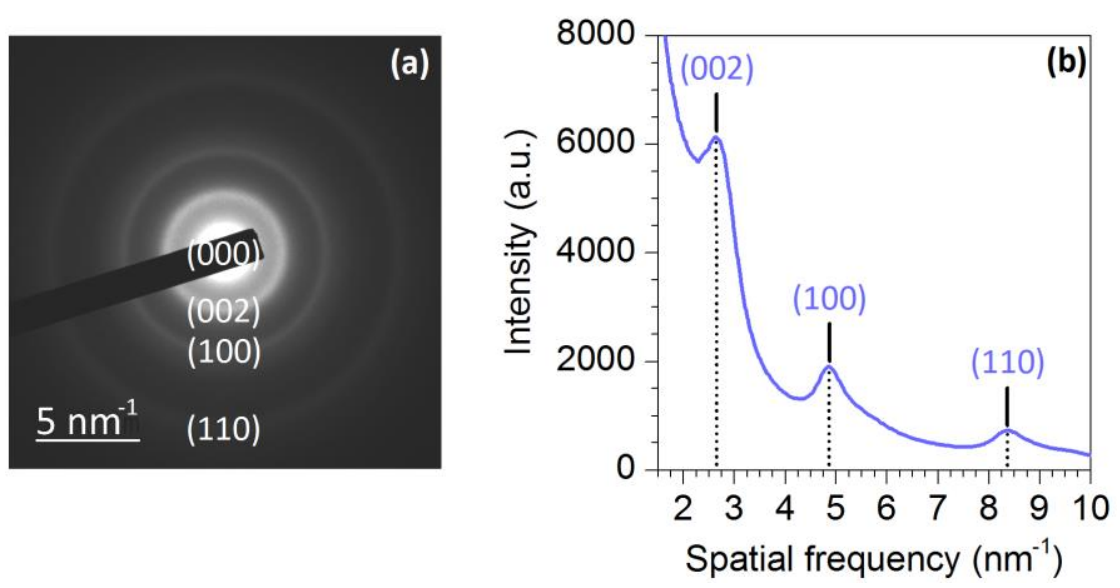

Figure 4. Typical diffractogram of soot aggregates, (a) emitted at $70 \%$ engine operating regimes. (b) Integrated intensity radial profile of (a) and position of the (002), (100) and (110) reflections in the reciprocal space. 

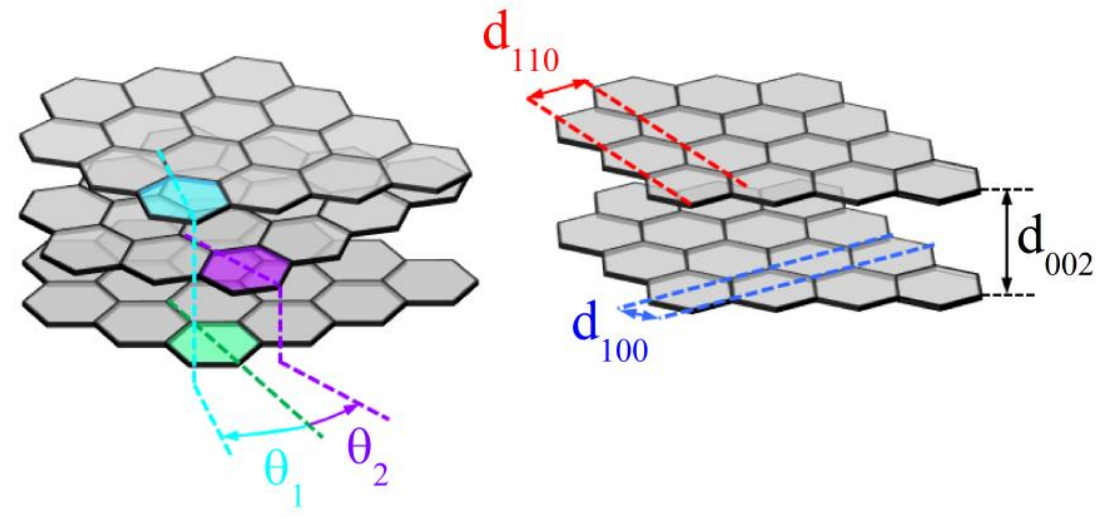

Figure 5. (a) Schematic representation of a turbostratic structure of carbon layers with random rotation angles $\theta_{1}$ and $\theta_{2}$. (b) Lattice spacing $d_{002}, d_{100}$ and $d_{110}$ giving rise to the SAED pattern. 

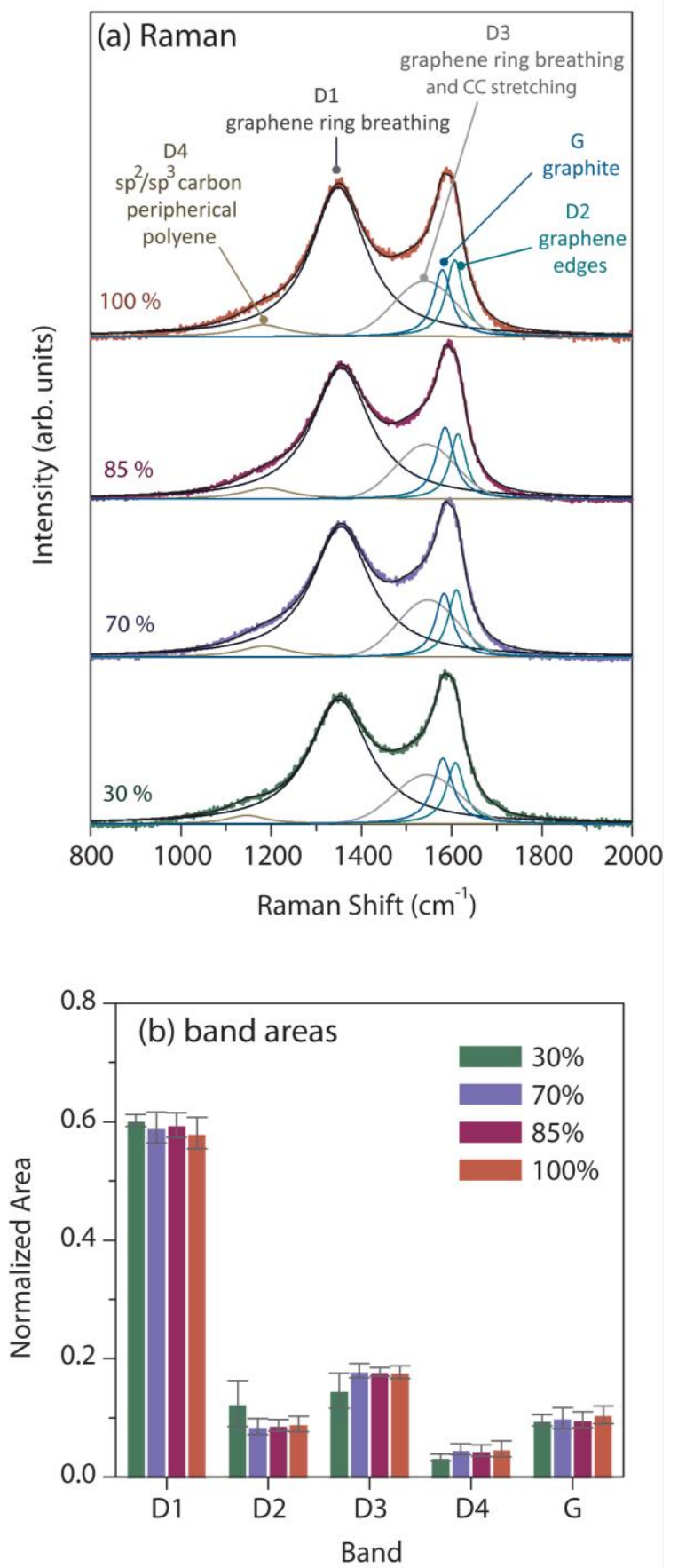

Figure 6. (a). Typical Raman spectra obtained for the samples corresponding to $30 \%, 70 \%, 85 \%$ and $100 \% F_{00}$ engine operating regimes. (b) Integrated band areas for each fitted band normalized to the total area. Error bars correspond to the standard deviation of the values obtained for different points within the same sample. Green, blue, purple, and orange bars correspond to the $30 \%, 70 \%$, $85 \%$, and $100 \% F_{00}$ engine operating regimes, respectively. 


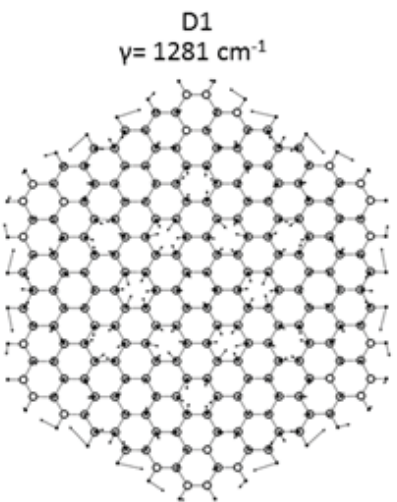

Normalized Intensity $=1$

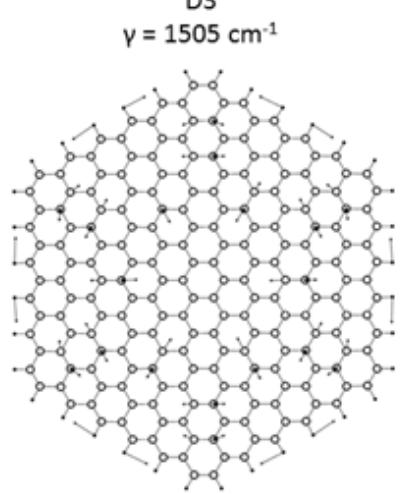

Normalized Intensity $=0.025$

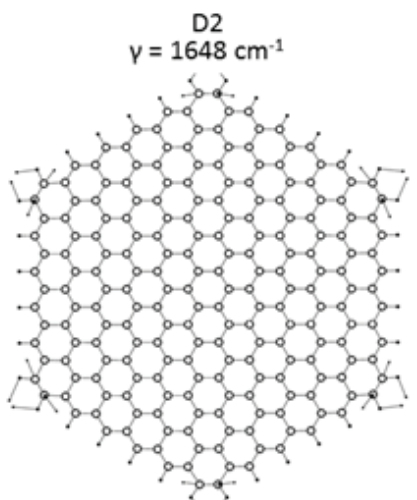

Normalized Intensity $=0.057$

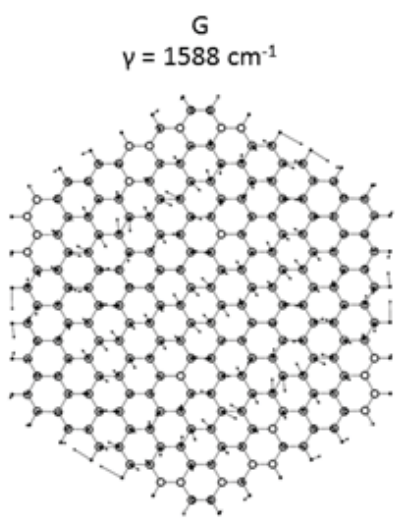

Normalized Intensity $=0.027$

Figure 7. Selected vibrational modes. The Raman normalized intensity and Raman shift $(\gamma)$ are shown for each mode. Arrows indicate the most significant vibrational motions of the carbon atoms. 

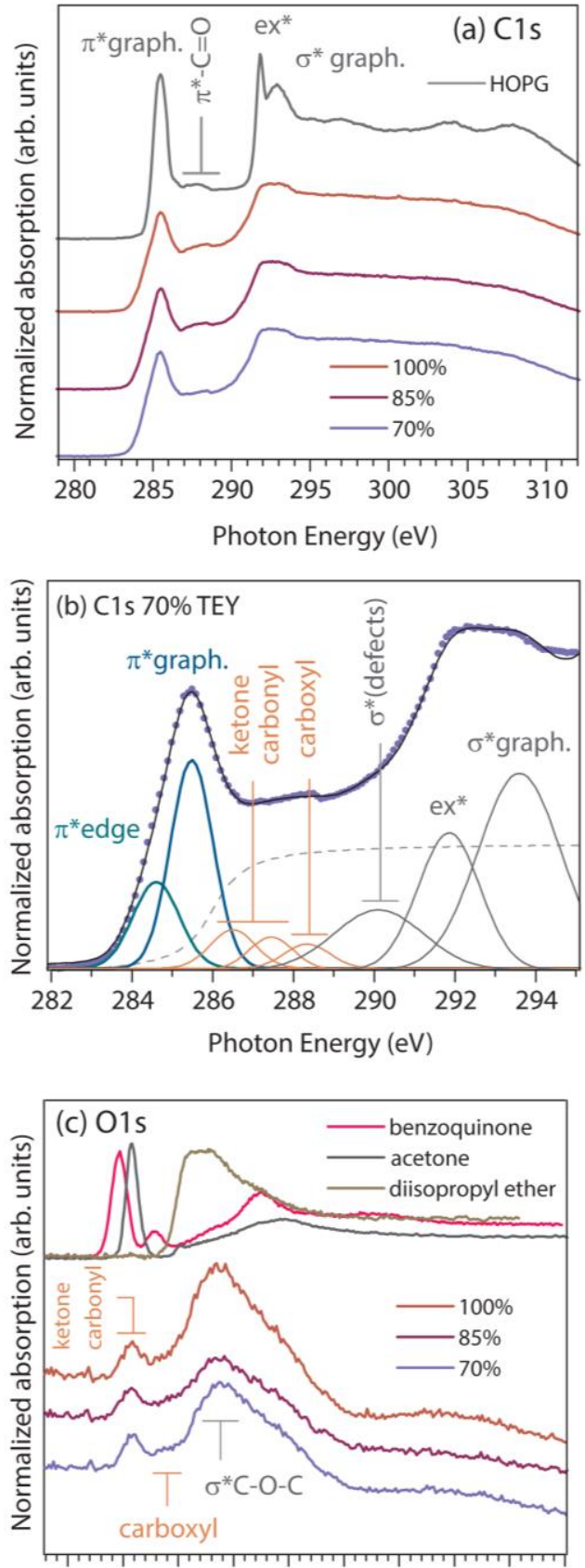

525530535540545550555560565570

Photon Energy (eV)
Figure 8. (a) Carbon K-edge NEXAFS spectra recorded in TEY (bulk signal) of the soot samples collected at $70 \%, 85 \%$ and $100 \%$ $F_{00}$ engine operating regimes, compared to graphite HOPG. The data are shifted for display. (b) Deconvolution of the 282-295 eV region exemplified on the $70 \% F_{00}$ engine operating regime (see text); black line: fit to the data. (c) Oxygen $K$-edge NEXAFS spectra recorded in TEY at the three regimes, compared with benzoquinone, acetone and diisopropyl ether for assignment purpose (see text). The data are shifted for display. 

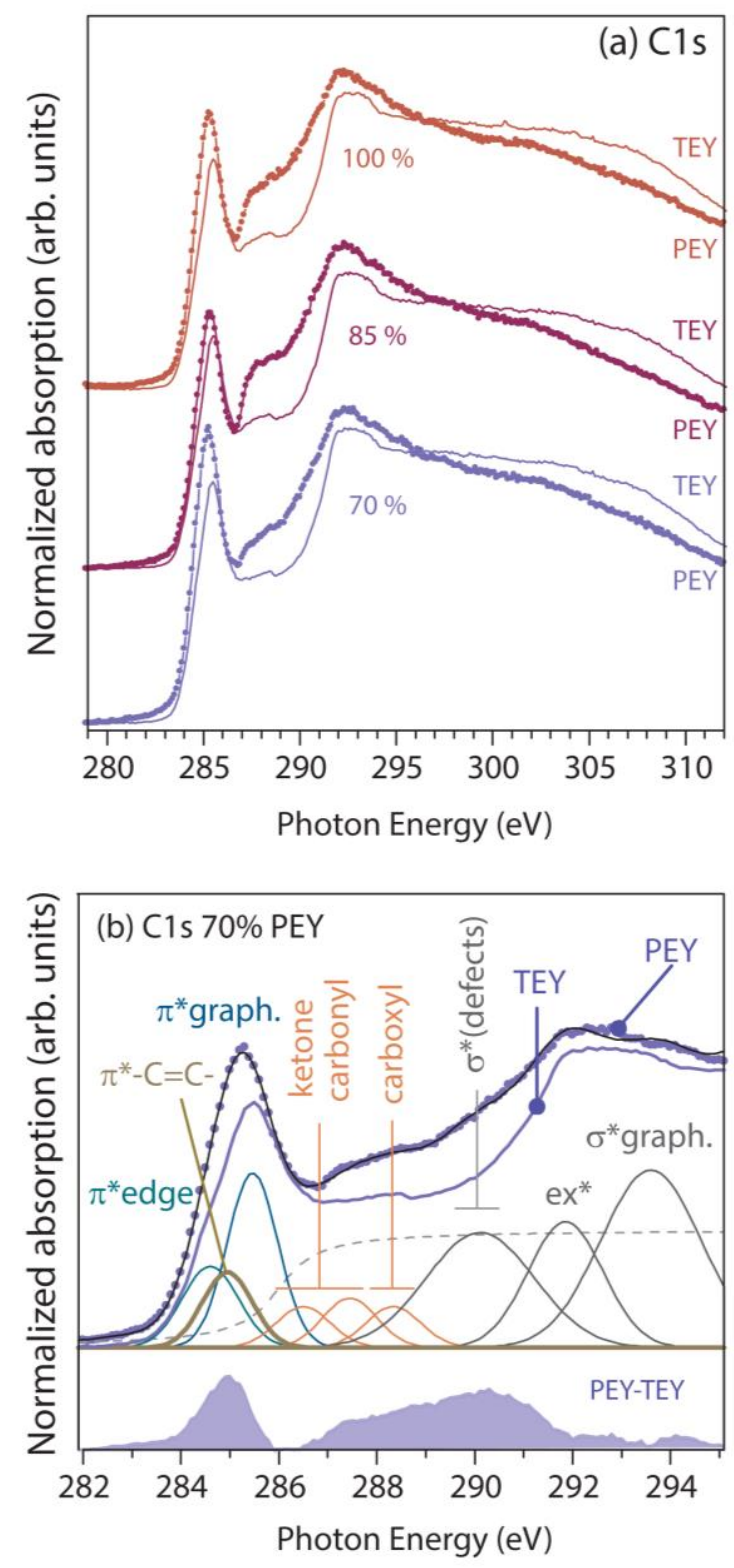

Figure 9. (a) Carbon K-edge NEXAFS spectra recorded in PEY (surface signal) of the soot samples collected at $70 \%, 85 \%$ and $100 \% F_{00}$ engine operating regimes, compared to the TEY spectra (bulk signal). The data are shifted for display. (b) Deconvolution (top) and PEYTEY difference (bottom) of the 282-295 eV region exemplified for the $70 \% \quad F_{00}$ engine operating regime; black line: fit to the data. 

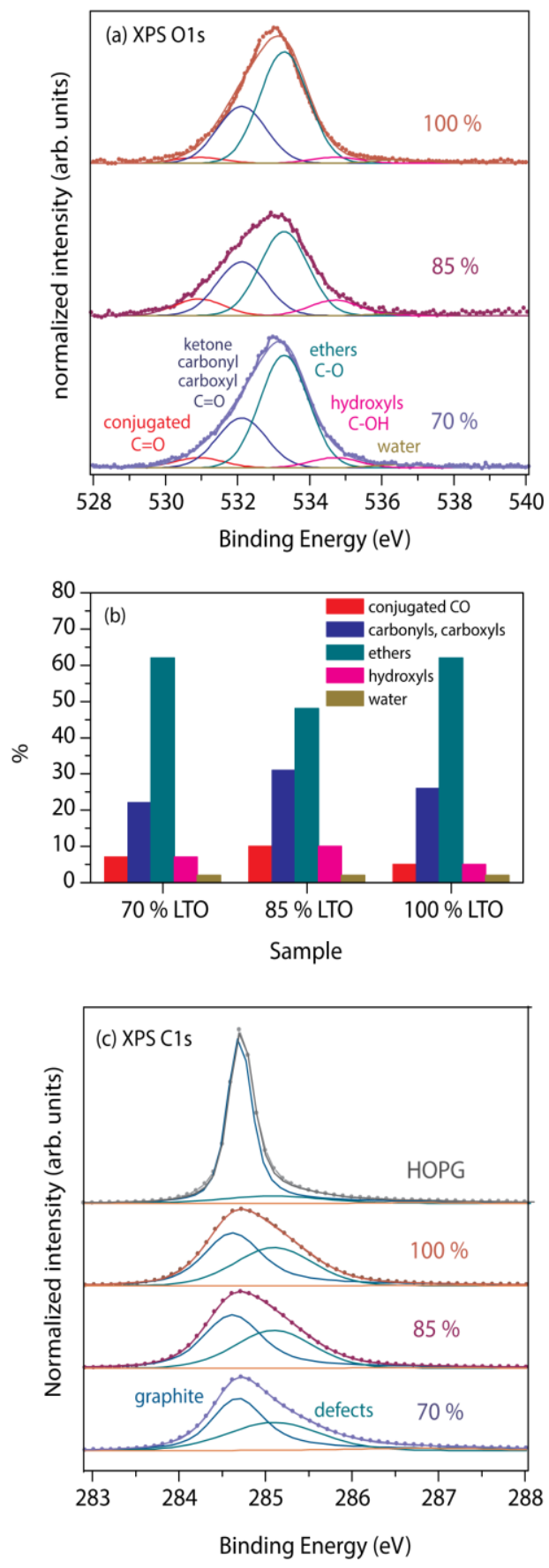

Figure 10. (a) O1s XPS of the soot samples collected at $70 \%$, $85 \%$ and $100 \% F_{00}$ regimes, with deconvolution in Gaussian components related to oxidized functionalities indicated on the figure. (b) Contribution of each component in the total Ols intensity (in \%). (c) Cls XPS of the soot samples collected at 70 $\%, 85 \%$ and $100 \%$ Foo engine operating regimes compared to HOPG, with deconvolution in Gaussian components related to carbon in graphitic and defective environments. 

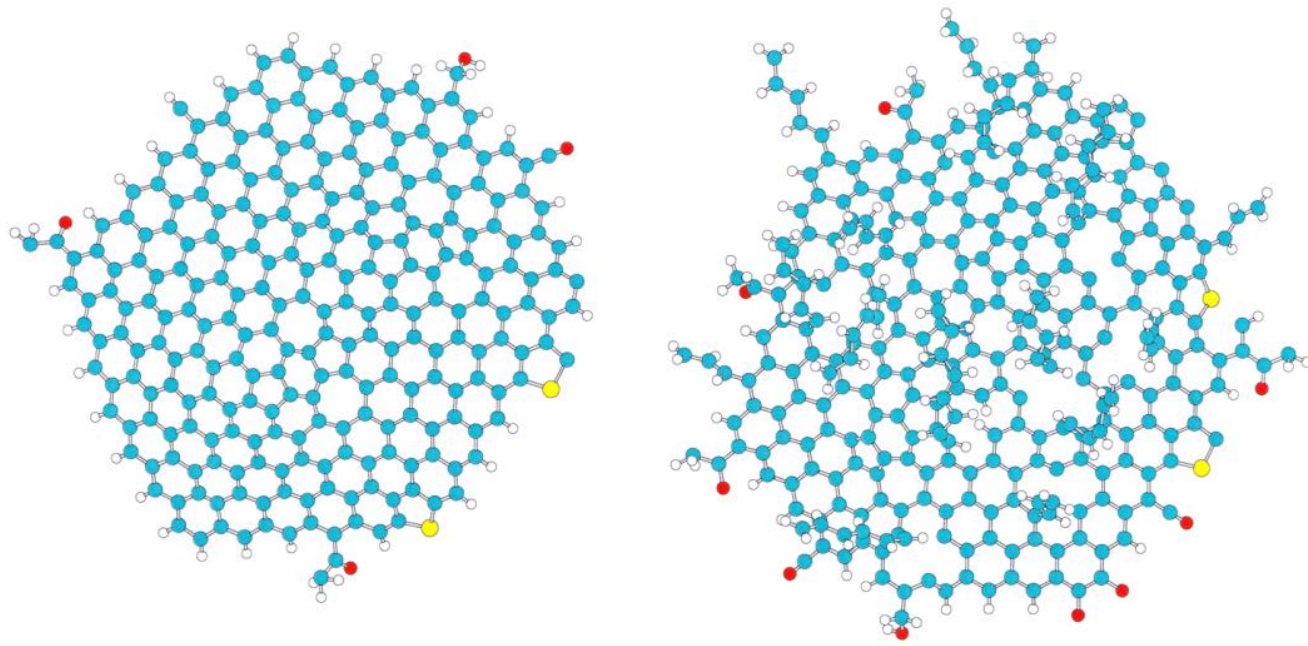

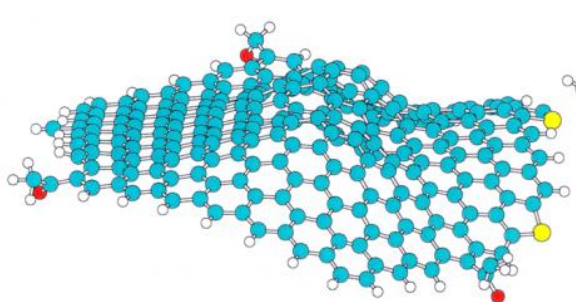

(a) Bulk

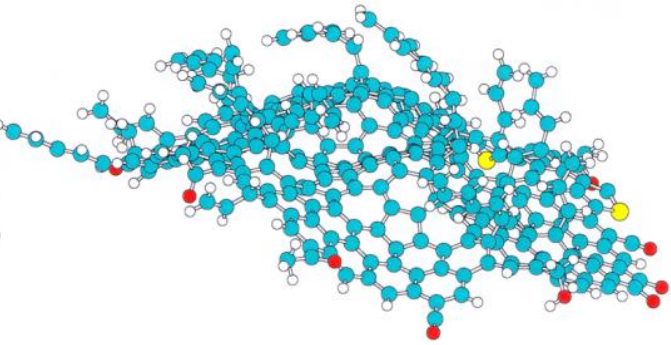

(b) Surface

Figure 11. Schematic representation of the graphene layers (top and side views); carbon is in blue, hydrogen in white, oxygen in red, sulfur in yellow. (a) Bulk layers are mostly graphitic of around $2.7 \mathrm{~nm}$ in length, with few topological defects such as heptagon-pentagons. Some oxidized groups ( $<2 \%$ at.) and traces of sulfur ( $<1 \%$ at.) are detected. (b) Surface layers are about the same size as those found in the bulk, with twice as much topological defects. In addition, around $30 \%$ of carbon atoms are located in unsaturated organic hydrocarbons; the surface is also more oxidized than the bulk (3\% at.). 